\title{
Working
}

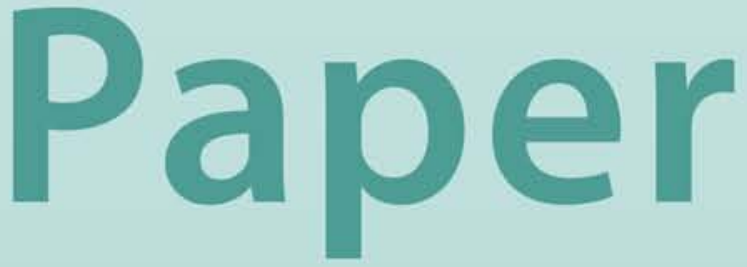


WP/04/63

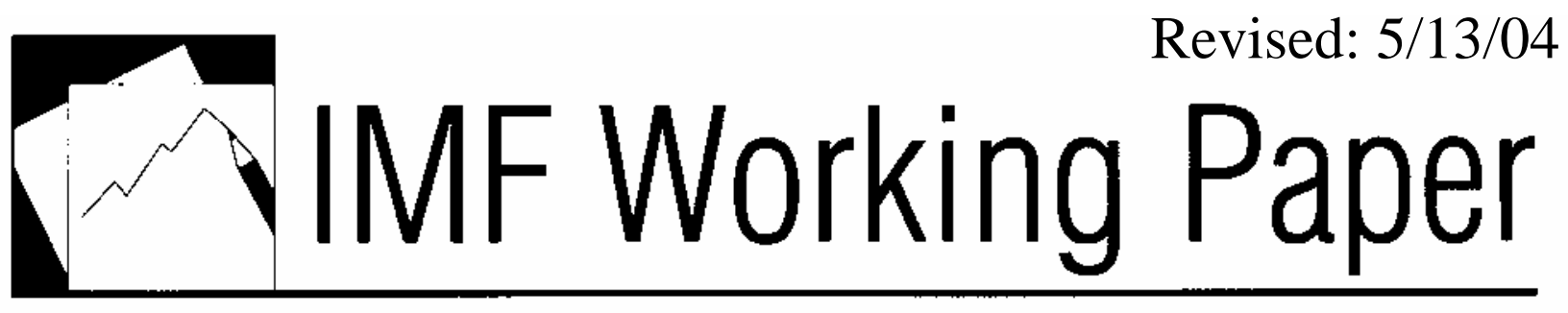

\section{Balance Sheets, Exchange Rate Policy, and Welfare}

Selim Elekdag and Ivan Tchakarov 


\title{
IMF Working Paper
}

Middle East and Central Asia Department and Research Department

Balance Sheets, Exchange Rate Policy, and Welfare

Prepared by Selim Elekdag and Ivan Tchakarov ${ }^{1}$

Authorized for distribution by Saade Chami and Gian Maria Milesi-Ferretti

April 2004

\begin{abstract}
This Working Paper should not be reported as representing the views of the IMF. The views expressed in this Working Paper are those of the author(s) and do not necessarily represent those of the IMF or IMF policy. Working Papers describe research in progress by the author(s) and are published to elicit comments and to further debate.

The debate about the appropriate choice of exchange rate regime is fundamental in international economics. This paper develops a small open-economy model with balance sheet effects and compares the performance of fixed and flexible exchange rate regimes. The model is solved up to a second-order approximation which allows us to address the issue of risk and welfare rigorously. The paper identifies threshold levels of the debt-to-GDP ratio above which fixed exchange rate regimes are welfare superior to monetary policy rules that imply flexible exchange rate regimes. The results suggest that emerging market economies that suffer from a relatively high level of indebtedness and are constrained in their pursuit of optimal monetary policy, could find it beneficial to opt for a fixed exchange rate regime.

JEL Classification Numbers: F31, F41

Keywords: Exchange rate policy, financial accelerator, debt-to-GDP threshold, second-order approximation

Author's E-Mail Address: selekdag@imf.org; itchakarov@imf.org

\footnotetext{
${ }^{1}$ Selim Elekdag is with the IMF's Middle East and Central Asia Department and Ivan Tchakarov is with the IMF's Research Department. The authors thank Tamim Bayoumi, Roberto Chang, Woon Gyu Choi, Gian Maria Milesi-Ferretti, Simon Gilchrist, Michael Devereux, and Douglas Laxton for useful comments and discussions. Susanna Mursula has been very helpful in developing the procedures used in the model simulations.
} 


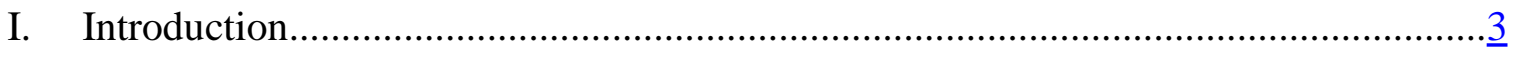

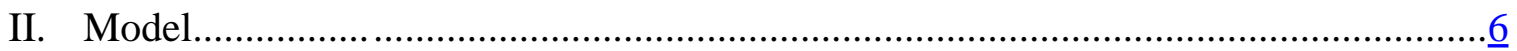

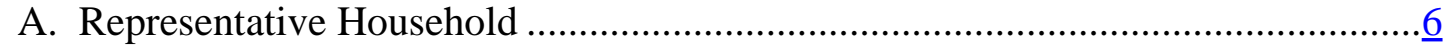

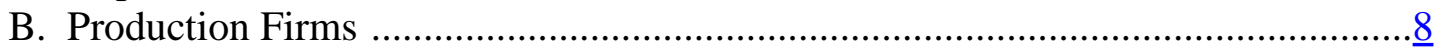

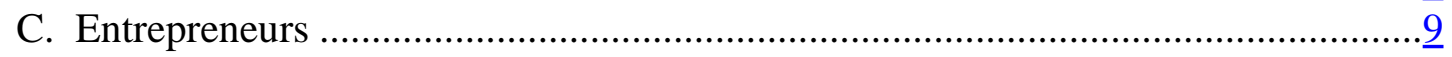

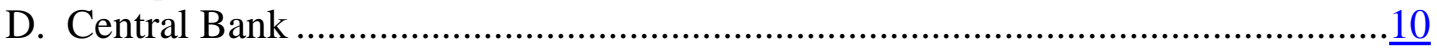

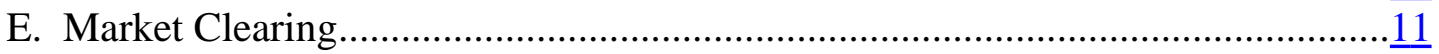

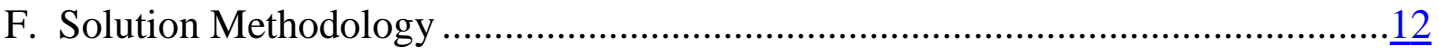

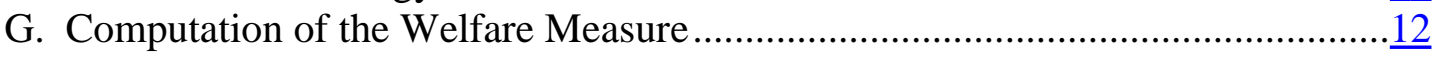

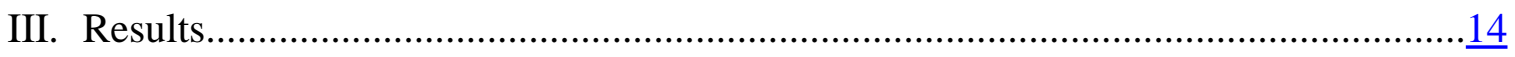

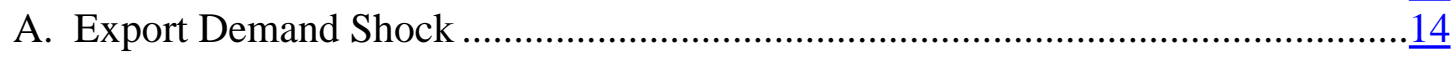

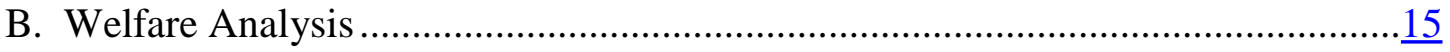

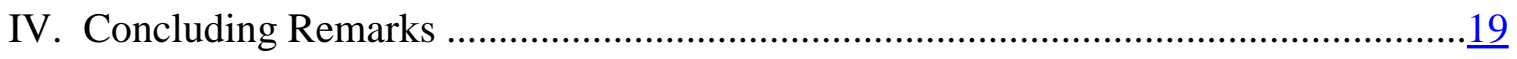

Tables:

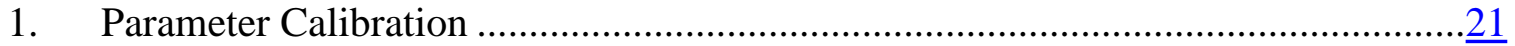

2. Regime Comparison.................................................................................

3. Detailed Regime Comparison ................................................................... $\frac{23}{24}$

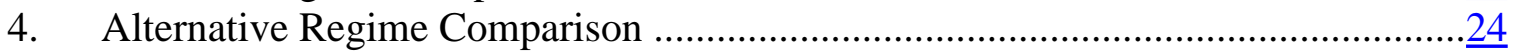

5. Comparisons with Other Regimes and Calibrations ..........................................

Figures:

1. Negative Export Shock under a Peg (No Financial Accelerator) ............................ $\underline{26}$

2. Negative Export Shock under a Float (No Financial Accelerator) .......................... 27

3. Negative Export Shock under a Peg (with Financial Accelerator) ..........................28

4. Negative Export Shock under a Float (with Financial Accelerator) ........................29

5. Welfare Comparison using a First-Order Approximation ................................... $\underline{30}$

6. Welfare Comparison using a Second-Order Approximation .................................

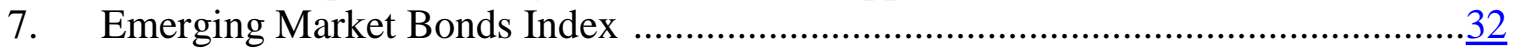

8. Alternative Welfare Comparison using a First-Order Approximation .....................33

9. Alternative Welfare Comparison using a Second-Order Approximation .................

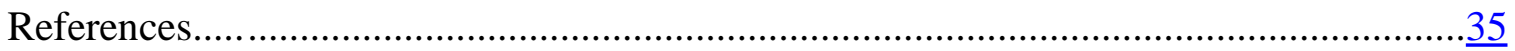




\section{INTRODUCTION}

After the severe financial crises that erupted in East Asia, the question of appropriate monetary policy for emerging market economies has received renewed attention. The common policy prescription that dates back to Friedman (1953) has advocated the implementation of flexible exchange rate regimes. A freely floating nominal exchange rate has the ability to act as a shock absorber and insulate the economy against external shocks. In a model with nominal rigidities, by allowing the currency to depreciate, the monetary authority facilitates a smoother adjustment relative to a fixed exchange rate regime.

However, emerging market economies are faced with two fundamental issues that complicate the conduct of monetary policy. First, these countries typically can only borrow in foreign currency denominations, a phenomenon called "Original Sin" by Eichengreen and Hausman (1999). Second, they are subject to a risk premium above and beyond the international lending rate. This premium in turn depends on the amount of collateral invested towards the project. The combination of these features that is referred to as the financial accelerator, collateral constraints or the balance sheet channel, creates a financially vulnerable environment. ${ }^{2}$ A sudden depreciation inflates liabilities that are denominated in foreign currency, thus reducing the value of collateral that can be used towards investment projects. As collateral evaporates, the risk premium that must be endured increases substantially, thus choking off the process of capital accumulation. This is one reason why many monetary authorities in emerging market economies have been reluctant to allow the currencies to float freely, and this is consistent with the "Fear of Floating" argument advanced by Calvo and Reinhart (2001). Even though a depreciation can potentially boost export volumes by promoting competitiveness, it can also trigger a potentially severe recession due to balance sheet effects and collateral constraints.

The incorporation of the financial accelerator channel has been introduced in a dynamic general equilibrium setting by Cespedes, Chang, and Velasco (2001, 2002); Devereux and Lane (2003); and Gertler, Gilchrist, and Natalucci (2003). These authors have made an important contribution to extending macroeconomic analysis to emerging market economies by incorporating balance sheet effects and collateral constraints in a standard small open-economy framework. The main conclusion of this line of research is consistent with the conventional wisdom embodied in the Mundell-Fleming framework, which promotes the implementation of flexible exchange rate regimes. This result is upheld even when such financial frictions are present in the model. A float can insulate the economy against adverse external shocks more effectively than a peg by allowing the currency to depreciate. The general consensus in these papers is that only in calibrations yielding "extreme" values of fundamentals can a peg be better than a float.

While the above literature has been instrumental in developing models that explicitly account for balance sheet effects, it has been limited to comparing the relative performance of fixed and flexible exchange rates by only investigating impulse response functions. For example, Cespedes,

2 We use the terms financial accelerator, collateral constraints, and balance sheet effects interchangeably in our analysis. 
Chang and Velasco (2002) contrast the behavior of different exchange rate regimes when the economy is subject to foreign interest rate and export shocks. Cespedes, Chang and Velasco (2001) recognize the limitations of this approach and construct an ad-hoc loss function. While their model is based on firm microfoundations, it is somewhat unsettling that they use a welfare metric that does not derive from first principles. Devereux and Lane (2003) conduct welfare analysis but ignore the effects of risk on the behavior of economic agents. ${ }^{3}$

In these models the consequences of uncertainty on welfare are impossible to analyze accurately. The main reason for this is the fact that researchers have typically resorted to linearization techniques to approximate the model and have, therefore, abstracted from higher moments. It is obvious then that, in a linear environment, it is impractical to ask the question if risk plays a significant role in affecting households' decisions. This stems from the fact that when a model is linearized, certainty equivalence holds, which does not allow agents to explicitly incorporate risk in their decision-making process. This seems to be much more important in a model where the main purpose is to account for the behavior of the risk premium associated with borrowing from abroad, and to analyze how economic agents change their decisions based on the capacity of different exchange rate regimes to mitigate such risks.

The main objective of this study is to conduct a welfare-based comparison of fixed and flexible exchange rate regimes. Our analysis builds on the model of Cespedes, Chang, and Velasco (2001, 2002), but carries out a rigorous welfare examination of this issue. This is made possible by a solution algorithm which can deal with second-order approximations to the equilibrium conditions of stochastic models. As has been emphasized by Cespedes, Chang, and Velasco (2001), the task of addressing these questions "...is not trivial, since there are a number of distortions (financial frictions in addition to sticky prices and monopoly power) and therefore Taylor approximations to the social objective function may not always yield the quadratic forms we have relied on." In such an environment a linear-quadratic approach, where one employs a quadratic approximation of the utility function, but evaluates it only with a linear approximation of the model equations, may lead to potentially spurious welfare results as has been emphasized by Kim and Kim (2003). Woodford (2001) has also shown that the usually employed linear approximations describing the equilibrium behavior of the model will represent a correct welfare ranking of alternative policy regimes only under very restrictive assumptions. The latter will not be met in any reasonably rich general equilibrium model, such as the one developed below.

While the balance sheet transmission mechanism has been found to provide useful insights in the debate about the appropriate choice of exchange rate regime, not much has been explored empirically about its quantitative implications. In this respect, another objective of this paper is to analyze quantitatively the relevance of this mechanism in explaining output behavior in the aftermath of a devaluation. For this purpose, we augment the model proposed by Cespedes, Chang, and Velasco ( 2002) by incorporating a monetary sector in terms of an interest rate rule, mutli-period price stickiness, a richer menu of financial assets, and introducing an economy-wide

3 This is because Devereux and Lane (2003) use a welfare metric that is not completely accurate since it is based on a linear-quadratic approach. See below for further details. 
technology shock in line with the real business cycle literature.

The main findings can be summarized as follows. We verify that a policy of strict inflation targeting is better than a fixed exchange rate from a welfare point of view in a world where the financial accelerator is not present, which serves to reinforce the policy recommendations of the Mundell-Fleming framework. Also, consistent with previous literature, welfare costs are higher in a model with the financial accelerator present, relative to the one without it for both fixed and flexible exchange rate regimes.

When the financial accelerator is present, we identify threshold values of the debt-to-GDP ratio above which the peg becomes superior to the float in terms of welfare. These thresholds are very sensitive to the approximation method. When we use a linear approximation, it is only when debt is above 31 percent of GDP that a flexible exchange rate delivers lower welfare. However, when we solve the model using a second-order approximation, properly account for the uncertainty inherently present in our framework, and conduct the welfare analysis correctly, the threshold drops to a much more plausible value of 16 percent.

The main message of this paper is to treat with caution the results obtained by the previous literature that consider collateral constraints and employ welfare metrics that are not rigorous. Not only do we demonstrate an accurate method of conducting welfare analysis, but much more importantly, we show that one can simulate cases where a peg dominates a float for a wide range of debt levels. ${ }^{4}$

We also provide different robustness checks that support the overall message of the paper. Similar results are obtained using versions of the Taylor rule, different degrees of the intratemporal elasticity of substitution between home and foreign goods, and varying degrees of openness.

Our results do not necessarily imply that fixed exchange rates are universally superior to flexible exchange rates. It is possible to entertain the case that optimally calibrated interest-rate rules that entail high exchange rate flexibility may yield higher welfare than a peg even for debt-to-GDP ratios of above 16 percent. In this sense, our analysis should not be viewed as an attempt to change the conventional policy recommendations prescribed by the Mundell-Fleming model.

At the same time, we believe that our results are useful in providing insights into the behavior of emerging market economies. If monetary authorities in such countries have to deal with macroeconomic imbalances in an environment characterized by weak institutional capacity, then a conscious policy of pursuing optimal behavior may be desirable, but difficult to achieve. In this respect, Hunt, Isard, and Laxton (2002) argue that optimal policy rules can be very sensitive to model specifications and, therefore, "...it could be dangerous for monetary authorities to use optimal rules as guidelines for policy."

4 Devereux (2004) provides an example of a model without balance sheet effects where a cooperative peg dominates a float. Choi and Cook (2004) develop a model with a banking system that operates in a similar fashion to the entrepreneurial sector, which also advocates a fixed exchange rate regime. 
The remainder of the paper is organized as follows. Section II lays out the model, Section III describes the results and Section IV concludes.

\section{MODEL}

Our basic modeling framework is an extension of Cespedes, Chang, and Velasco (2002), where we focus on a small open economy with a representative household, producers, entrepreneurs, and a central bank. The economy produces a composite consumption good and imports a foreign good. The domestic good is a bundle that is composed of a continuum of goods produced by domestic firms in a monopolisitically competitive environment. These firms each supply a differentiated good and hence enjoy market power, which they exploit to maximize their profits. This warrants active cyclical monetary policy. To this end, we incorporate a central bank that uses an interest rate rule to achieve specific policy objectives. The representative household is allowed to accumulate financial assets and is thus responsive to interest rate fluctuations.

\section{A. Representative Household}

The household is infinitely lived and its preferences are defined over aggregate consumption, $C_{t}$, and labor effort, $L_{t}$, which are described by the following utility function:

$$
E_{0} \sum_{t=0}^{\infty} \beta^{t}\left[\frac{C_{t}^{1-\sigma}}{1-\sigma}-\chi \frac{L_{t}^{1+\psi}}{1+\psi}\right]
$$

where $E_{t}$ denotes the mathematical expectation conditional on information available in period $t$, and $\beta \in(0,1)$ is the subjective discount factor.

Aggregate consumption is a bundle consisting of a domestically produced good and an imported foreign good:

$$
C_{t}=\kappa C_{H t}^{\gamma} C_{F t}^{1-\gamma}
$$

where $C_{H t}$ denotes the consumption of the home good, $C_{F t}$ consumption of the imported good, and $\kappa=\left[\gamma^{\gamma}(1-\gamma)^{1-\gamma}\right]^{-1}$ is a normalizing constant.

Following Cespedes, Chang and Velasco (2002), we assume that the price of the imported good is normalized to unity in terms of foreign currency. Also, imports are assumed to be freely traded and the Law of One Price holds, so that the domestic currency price of imports is just equal to the nominal exchange rate $S_{t}$. The aggregate price level, $Q_{t}$, is then derived by solving for the minimum expenditure required to obtain one unit of the aggregate consumption good. Denoting the price of the of the domestic good as $P_{t}$, the aggregate price level it then:

$$
Q_{t}=P_{t}^{\gamma} S_{t}^{1-\gamma}
$$


Given the aggregate price index, the individual consumption demands for each good can be derived:

$$
\begin{aligned}
C_{H t} & =\gamma\left(\frac{P_{t}}{Q_{t}}\right)^{-1} C_{t} \\
C_{F t} & =(1-\gamma)\left(\frac{S_{t}}{Q_{t}}\right)^{-1} C_{t}
\end{aligned}
$$

The domestic good is itself a composite good, consisting of a CES aggregate of the continuum of differentiated domestic goods, more specifically:

$$
C_{H t}=\left[\int C_{H j t}^{\frac{\lambda-1}{\lambda}} d j\right]^{\frac{\lambda}{\lambda-1}}
$$

where $j \in[0,1]$ and $\lambda>1$. Each unique good $C_{H j t}$, is produced by a monopolistically competitive firm. This gives each firm market power which motivates price stickiness.

The household's budget constraint in period $t$ is as follows:

$$
Q_{t} C_{t}+Q_{t} \Gamma_{t}+B_{t+1}+S_{t} F_{t+1}^{*}=W_{t} L_{t}+\Pi_{t}+\left(1+i_{t-1}\right) B_{t}+\left(1+i_{t-1}^{*}\right) S_{t} F_{t}^{*}
$$

where $B_{t+1}$ and $F_{t+1}^{*}$ are nominal stocks of domestic and foreign currency denominated bonds maturing in period $t$, which earn interest $i_{t-1}$ and $i_{t-1}^{*}$ respectively. ${ }^{5}$ Households earn wage $W_{t}$ for their labor services $L_{t}$. Since they own the domestic production firms, they retain any profits, $\Pi_{t}$. Finally, households must incur an intermediation cost, $\Gamma_{t}$, which has the following specification:

$$
\Gamma_{t}=\frac{\phi_{B}}{2}\left(\frac{B_{t+1}}{Q_{t}}\right)^{2}+\frac{\phi_{F^{*}}}{2}\left(\frac{S_{t} F_{t+1}^{*}}{Q_{t}}\right)^{2}
$$

where $\phi_{B}, \phi_{F^{*}} \geqslant 0$ and $\phi_{B}+\phi_{F^{*}}>0$. Without this cost, the stocks of bonds and consumption would not be stationary, preventing the model from being solved using the Sims (2000) method.

The household chooses the paths of $\left\{C_{t}, L_{t}, B_{t}, F_{t}^{*}\right\}_{t=0}^{\infty}$ to maximize its expected lifetime utility (1) subject to the constraint (7) and initial values for $B_{0}$ and $F_{0}$. Ruling out Ponzi-type schemes, we get the following first-order conditions:

5 It is important to note that, as is common in the literature, we too assume that $B_{t+1}$ and $F_{t+1}^{*}$ are zero in the non-stochastic steady state. 


$$
\begin{gathered}
\chi \frac{L_{t}^{\psi}}{C_{t}^{-\sigma}}=\frac{W_{t}}{Q_{t}} \\
C_{t}^{-\sigma}\left[1+\phi_{B} B_{t+1}\right]=\beta\left(1+i_{t}\right) E_{t}\left[C_{t+1}^{-\sigma} \frac{Q_{t}}{Q_{t+1}}\right] \\
C_{t}^{-\sigma}\left[1+\phi_{F^{*}} S_{t} F_{t+1}^{*}\right]=\beta\left(1+i_{t}^{*}\right) E_{t}\left[C_{t+1}^{-\sigma} \frac{Q_{t}}{Q_{t+1}} \frac{S_{t+1}}{S_{t}}\right]
\end{gathered}
$$

The first condition implies that the household equates its marginal rate of substitution between consumption and leisure to the real wage, $W_{t} / Q_{t}$. The last two first-order conditions are the familiar Euler equations which emphasize the household's preference to smooth consumption. Abstracting from the intermediation costs, they can be combined to yield the familiar uncovered interest parity condition.

\section{B. Production Firms}

The economy is populated by a multitude of monopolistically competitive firms each producing a unique good. The production technology for an arbitrary firm $j \in[0,1]$ is:

$$
Y_{j t}=A_{t} K_{j t}^{\alpha} L_{j t}^{1-\alpha}
$$

where, $A_{t}$, is the technology shock common to all production firms. The household provides the labor services and capital, $K_{j t}$, is provided by the entrepreneurs to be described below. Production firms exploit their market power and set prices in order to maximize profits along a downward sloping demand curve given by:

$$
Y_{j t}=\left(\frac{P_{j t}}{P_{t}}\right)^{-\lambda} Y_{t}
$$

Following Rotemberg (1982), we assume that it is costly to adjust prices because of quadratic menu costs. Hence, an arbitrary firm maximizes the discounted stream of profits given by:

$$
E_{0} \sum_{t=0}^{\infty} \rho_{t, t+1}\left[P_{j t}-M C_{t}-A C_{j t}\right] Y_{j t}
$$

where the quadratic price adjustment cost $A C_{j t}$ and marginal cost $M C_{t}$ are defined as: 


$$
\begin{aligned}
A C_{j t} & =\frac{\varphi}{2} \frac{\left(P_{j t}-P_{j, t-1}\right)^{2}}{P_{j, t-1}} \\
M C_{t} & =\frac{R_{t}^{\alpha} W_{t}^{1-\alpha}}{A_{t} \alpha^{\alpha}(1-\alpha)^{1-\alpha}}
\end{aligned}
$$

Firms are owned by the household, hence the present future value of profits are discounted according to the household's intertemporal marginal rate of substitution in consumption, which implies:

$$
\rho_{t, t+1}=\beta \frac{C_{t+1}^{-\sigma}}{C_{t}^{-\sigma}} \frac{Q_{t}}{Q_{t+1}}
$$

The profit maximization problem implies a trade-off between capital and labor inputs that depends on the relative cost of each of them, and price setting behavior:

$$
\begin{gathered}
\alpha R_{t} K_{t}=(1-\alpha) W_{t} L_{t} \\
1=\lambda\left[1-\frac{M C_{t}}{P_{j t}}-\frac{\varphi}{2} \frac{\left(P_{j t}-P_{j, t-1}\right)^{2}}{P_{j, t-1}}\right]-\frac{\varphi}{2} E_{t}\left[\beta\left(\frac{P_{j t+1}^{2}}{P_{j t}^{2}}-1\right) \frac{Y_{j t+1}}{Y_{j t}}\right]+\varphi\left(\frac{P_{j t+1}}{P_{j t}}-1\right)
\end{gathered}
$$

Equation (19) is a New Keynesian Phillips' curve which reverts to the familiar mark-up rule when there are no adjustment costs $(\varphi=0)$ :

$$
P_{j t}=\frac{\lambda}{\lambda-1} M C_{t}
$$

\section{Entrepreneurs}

One of our main objectives in this paper is to analyze the consequences of balance sheet effects in the simplest framework possible. Therefore we adapt the structure introduced by Cespedes, Chang, and Velasco (2002) when introducing the financial accelerator in an open economy context. Although the inclusion of entrepreneurs is crucial to our investigation, we provide only a concise presentation and refer the reader to the work of Cespedes, Chang, and Velasco (2002) along with Bernanke, Gertler, and Gilchrist (2000) for further details.

Entrepreneurs finance investment partly with foreign loans subject to frictions. In any given 
period, the entrepreneur is assumed to have some net worth denominated in domestic currency. When the entrepreneur engages in capital accumulation and the investment outlays exceed net worth, the entrepreneur must finance the remainder by borrowing foreign currency denominated assets from abroad. Hence the entrepreneur is subject to the following budget constraint:

$$
P_{t} N_{t}=Q_{t} K_{t+1}-S_{t} D_{t+1}^{*}
$$

where, $N_{t}$ and $D_{t+1}^{*}$, denote net worth and foreign currency denominated debt, respectively. It is important to notice that net worth is equal to assets minus foreign currency denominated liabilities. This highlights one channel by which net worth is susceptible to exchange rate fluctuations.

Entrepreneurs are risk neutral and choose $D_{t+1}^{*}$ and $K_{t+1}$ to maximize profits. We assume that capital depreciates completely in production. Due to informational asymmetries, the expected return to investment is equal to the foreign interest rate augmented by a risk premium $\eta_{t+1}$, that is:

$$
E_{t}\left[\frac{R_{t+1} K_{t+1} / S_{t+1}}{Q_{t} K_{t+1} / S_{t}}\right]=\left(1+i_{t+1}^{*}\right)\left(1+\eta_{t+1}\right)
$$

Bernanke, Gertler and Gilchrist (2000) show that the risk premium can be expresses as an increasing function of the value of investment relative to net worth:

$$
\left(1+\eta_{t+1}\right)=\Psi\left(\frac{Q_{t} K_{t+1}}{P_{t} N_{t}}\right)
$$

where $\Psi(\cdot)=1$. and $\Psi(\cdot)^{\prime}>0$.

At the beginning of each period, entrepreneurs collect returns from capital and honor their foreign debt obligations. Since it will be assumed that they consume a fraction $(1-\delta)$ of the remainder on imports, net worth evolves according to the following formulation:

$$
P_{t} N_{t}=\delta\left[R_{t} K_{t}-\left(1+i_{t}^{*}\right)\left(1+\eta_{t}\right) S_{t} D_{t}^{*}\right]
$$

This equation highlights the vulnerability of domestic currency denominated net worth to sudden depreciations and foreign interest rate fluctuations. ${ }^{6}$

\section{Central Bank}

In order to conduct more realistic monetary policy analysis, we include a central bank in our model. The central bank implements a general interest rate rule in order to achieve specific policy objectives. Monetary policy is specified as in Kollmann (2002) in terms of an interest rate rule of

6 Cespedes (2000) and Gerter, Gilchrist, and Natalucci (2003) each provide additional details as well as novel extensions. Finally, see Bernanke, Gertler, and Gilchrist (2000) for the full exposition. 
the form:

$$
i_{t}=\bar{\imath}+\zeta_{\pi} \widehat{\pi}_{t}+\zeta_{y} \widehat{y}_{t}+\zeta_{S} \widehat{\left(\frac{S_{t}}{S_{t-1}}\right)}
$$

where monetary authorities adjust the nominal interest rate in accordance with the inflation rate, the current output gap and nominal exchange rate depreciation. Notice that when $\zeta_{\pi} \rightarrow \infty$ the central bank is strictly targeting inflation and when $\zeta_{s} \rightarrow \infty$ the bank is implementing a fixed exchange rate regime. As a robustness check, we also try the classic Taylor rule, where $\zeta_{\pi}=1.5$ and $\zeta_{y}=0.5$, and an extension where $\zeta_{s}=0.5$, which we call the augmented Taylor Rule $(A T R)$.

\section{E. Market Clearing}

Domestic expenditure on home goods is a fraction $\gamma$ of final expenditures. The home good is also sold to foreigners, which is assumed to be an exogenous process $X_{t}$. The market clearing condition for home goods is thus:

$$
P_{t} Y_{t}=\gamma Q_{t}\left[K_{t+1}+C_{t}\right]+S_{t} X_{t}
$$

The market for domestic bonds must also clear, which implies:

$$
B_{t}=0
$$

The exogenous variables are all assumed to be simple $A R(1)$ processes:

$$
\begin{aligned}
i_{t}^{*}-i^{*} & =\vartheta_{i^{*}}\left(i_{t-1}^{*}-i^{*}\right)+\varepsilon_{i t} \\
A_{t} & =\vartheta_{A} A_{t-1}+\varepsilon_{A t} \\
X_{t} & =\vartheta_{X} X_{t-1}+\varepsilon_{X t}
\end{aligned}
$$

Finally, to close the model, we need to explicitly define the inflation rate:

$$
\pi_{t}=\frac{Q_{t}}{Q_{t-1}}
$$

Assuming all firms behave symmetrically, the stationary rational expectations equilibrium is a set of stationary stochastic processes $\left\{Q_{t}, P_{t}, S_{t}, B_{t+1}, F_{t+1}^{*}\right.$, $\left.D_{t+1}^{*}, W_{t}, L_{t}, R_{t}, i_{t}, i_{t}^{*}, Y_{t}, K_{t+1}, N_{t}, M C_{t}, \eta_{t+1}, \pi_{t}, A_{t}, X_{t}\right\}_{t=0}^{\infty}$ satisfying equations (3), (7), (9)-(12), (16), (18)-(19) and (21)-(31) along with initial conditions $B_{0}, F_{0}^{*}$, and $D_{0}^{*}$. 


\section{F. Solution Methodology}

In this section we review the calibration of the model, the solution of the steady-state values of the variables, and the accurate second-order approximation. We follow Cespedes, Chang and Velasco (2002) when calibrating the model. The parameters are depicted in Table 1. Here we provide a succinct review of a few parameters. The elasticity of substitution between the differentiated goods, $\lambda$, is set at 10, which implies a markup of 11 percent. The price adjustment cost, $\varphi$, is chosen to be 200. Consistent with Kollmann (2002) and Lane and Milesi-Ferretti (2001), the adjustment costs on the domestic bond, $\phi_{B}$, and foreign currency bond, $\phi_{F^{*}}$, are set at zero and 0.0019 , respectively. For our benchmark calibration we choose the elasticity of the risk premium with respect to the net worth to capital ratio to be 0.02 . When this elasticity is zero, the financial accelerator channel in the model is shut down and the risk premium is no longer endogenously determined. We vary the probability of business failure from our base line of 0.272 to investigate a broad range of steady-state levels of the risk premium.

We calibrate the persistence and variance of the foreign interest rate and technology shocks by following Kollmann (2002). The persistence and standard deviation of the technology shock are set, respectively, at 0.9 and 0.01 , and the persistence and standard deviation of the interest rate shock are set at 0.75 and 0.004 . For the export shock we use the demeaned weighted average of the Hodrick-Prescott filtered log real export volume series of major emerging markets. ${ }^{7}$ Using a parsimonious AR(1) specification, we estimate the persistence and standard deviation of this shock to be 0.5 and 0.08 , respectively.

Now that the parameters are calibrated, we move on to the solution of the steady-state variables. The steady state of the nonlinear model is solved numerically in portable Troll. The routine breaks a large nonlinear simulation problem into a number of smaller steps and applies the Newton-Raphson algorithm iteratively to each step. ${ }^{8}$ Separating the large, nonlinear problem into smaller steps allows the algorithm to treat the subproblems as approximately linear without breaking down. We calculate the impulse response functions using a variant of this algorithm that allows us to compute the forward-looking solution of the nonlinear dynamic model under perfect foresight about the underlying realizations of the stochastic processes. The second-order approximation of the solution is computed in DYNARE using Sims (2000). ${ }^{9}$

\section{G. Computation of the Welfare Measure}

A second-order Taylor expansion of the utility function yields:

7 Data from the IMF's IFS database was obtained on the following countries: Argentina, Brazil, Chile, Indonesia, Korea, Malaysis, Mexico, the Philippines, Russia, Thailand and Turkey.

8 These algorithms were programmed in TROLL by Susanna Mursula, at the IMF. For a fuller description, see Juillard and Laxton (2003).

9 The DYNARE toolbox runs under MATLAB and can be downloaded from the DYNARE website at http://www.cepremap.cnrs.fr/dynare. For more on DYNARE, see Collard and Juillard (2003), and Juillard and Laxton (2003). 


$$
E U_{t}=\bar{U}+\bar{C}^{1-\rho} E\left(\hat{C}_{t}\right)-\frac{1}{2} \rho \bar{C}^{1-\rho} \operatorname{var}\left(\hat{C}_{t}\right)-\bar{L}^{1+\psi} E\left(\widehat{L}_{t}\right)-\frac{1}{2} \psi \bar{L}^{1+\psi} \operatorname{var}\left(\widehat{L}_{t}\right)
$$

In computing the welfare implications from the shocks we follow Lucas (1987) in that we represent them as the permanent shift in steady-state consumption required to achieve the same expected utility. That is, we find how much steady state consumption the household is ready to give up in order to negate the effect of the shocks. Since we use a second-order approximation, however, we can go even further. We can decompose the effects of a particular shock to the dynamic system. The shock matters because it influences the expected levels of the variables and because it has a bearing on the their second moments. While the latter can be found relatively easy from a first-order solution, the former can be gleaned only from a full second-order expansion of the model. Let $\xi^{\text {mean }}$ denote the permanent shift in steady-state consumption that delivers the same expected utility. Then making use of (32) we must have that

$$
U\left(\left(1+\xi^{\text {mean }}\right) C, L\right)=\frac{\left(\left(1+\xi^{\text {mean }}\right) \bar{C}\right)^{1-\rho}}{1-\rho}-\frac{\bar{L}^{1+\psi}}{1+\psi}=\bar{U}+\bar{C}^{1-\rho} E\left(\hat{C}_{t}\right)-\bar{L}^{1+\psi} E\left(\widehat{L}_{t}\right)
$$

Solving for $\xi^{\text {mean }}$ we get:

$$
\xi^{\text {mean }}=\left[1+(1-\rho) E\left(\hat{C}_{t}\right)-\frac{(1-\rho) \bar{L}^{1+\psi}}{\bar{C}^{1-\rho}} E\left(\widehat{L}_{t}\right)\right]^{\frac{1}{1-\rho}}-1
$$

In a similar fashion we derive $\xi^{\text {variance }}$, which denotes the permanent shift in steady-state consumption associated with the effect of the shocks on the variances of the variables. We find that:

$U\left(\left(1+\xi^{\text {variance }}\right) C, H\right)=\frac{\left(\left(1+\xi^{\text {variance }}\right) \bar{C}\right)^{1-\rho}}{1-\rho}-\frac{\bar{L}^{1+\psi}}{1+\psi}=-\rho \bar{C}^{1-\rho} \operatorname{var}\left(\hat{C}_{t}\right)-\psi \bar{L}^{1+\psi} \operatorname{var}\left(\widehat{L}_{t}\right)$.

Thus $\xi^{\text {variance }}$ can be found:

$$
\xi^{\text {variance }}=\left[1-\frac{1}{2} \rho(1-\rho) \operatorname{var}\left(\hat{C}_{t}\right)-\frac{1}{2} \psi \frac{(1-\rho) \bar{L}^{1+\psi}}{\bar{C}^{1-\rho}} \operatorname{var}\left(\widehat{L}_{t}\right)\right]^{\frac{1}{1-\rho}}-1
$$

In the usual log-linear approximation of the model $\xi^{\text {mean }}$ will be equal to zero, since the second moments of the model are not present in the solution and, therefore, $E\left(\hat{C}_{t}\right)=E\left(\widehat{L}_{t}\right)=0$. In our framework, the consumption and labor choices of the representative agent will be affected by the variability of the shocks. This will also have a direct bearing on the welfare calculations. ${ }^{10}$ 


\section{RESULTS}

Before moving on to the main results on welfare, it is useful to inspect how external shocks are propagated to the small open economy. There are several papers in the literature that consider the impact of shocks on an economy with collateral constraints using impulse response analysis including Cook and Devereux (2001); Cespedes, Chang, and Velasco (2002); Devereux and Lane (2003); Elekdag (2003); and Gertler, Gilchrist, and Natalucci (2003). Here we only investigate the impact of an export shock to reinforce our understanding of model dynamics. Although impulse responses are extremely useful to see how the model responds to disturbances, it is crucial to emphasize that no accurate welfare implications can be inferred from them. This is because standard impulse response analysis utilized in the literature considers only linear dynamics and, hence, does not incorporate the impact of second-order terms necessary for accurate welfare analysis. Even more importantly, a rigorous welfare exercise requires examining the response of the model not only to one-time shocks, but its stochastic equilibria under alternative policy regimes.

\section{A. Export Demand Shock}

In Figures 1-4, we consider a 1 percent decrease in export demand. The first two figures consider the case without the financial accelerator under the peg and the float respectively. The last two figures examine the case with collateral constraints. Our results are consistent with those of Cespedes, Chang and Velasco (2002) and we refer the reader to their work for further details. Here we only attempt to highlight a few key features of the model. ${ }^{11}$

In all the figures the decline in export demand leads to a recession, higher unemployment and a real depreciation. Although domestic interest rates decrease, we still see contractionary real depreciations in all of the cases. Examination of the four experiments yields two notable features. First, with the financial accelerator in effect shocks are indeed amplified and do destabilize the economy more than under the case without collateral constraints. Second, the economy reverts back to equilibrium at a slower rate in the presence of the financial accelerator channel. Balance sheet effects and collateral constraints amplify and protract the impact of shocks.

When the financial accelerator is not present, the float seems to insulate the economy more effectively against external shocks, as can be seen when comparing Figures 1 and 2 . In the case when the financial accelerator is operational, this distinction is less obvious and thus warrants a quantitative assessment, which we now turn to.

employ a similar welfare metric.

11 It should be noted that before extending the Cespedes, Chang and Velasco (2002) framework, we were able to replicate their results exactly. Other authors that consider an export demand shock include Cespedes, Chang and Velasco (2001). For interest rates shocks, see Cespedes (2000) and Gertler, Gilchrist and Natalucci (2003). Finally, for terms of trade shocks, see Devereux and Lane (2003) and Elekdag (2003). 


\section{B. Welfare Analysis}

Tables 2 to 5 and Figures 5 to 9 present the main contributions of the paper. Table 2 concentrates on the core results from our benchmark calibration, where the welfare ranking of the main exchange rate regimes are considered. Table 3 provides a more detailed analysis of the benchmark case, where we present welfare results for different debt-to-GDP ratios. Table 4 displays the results from a calibration that assumes that the steady-state risk premium is set at 8 percent, which is consistent with the average value of the EMBI index over the last 13 years as shown in Figure 7. Table 5 provides robustness checks by including the welfare properties of the standard Taylor rule and the augmented Taylor rule, and of cases where the intratemporal elasticity of substitution and the degree of openness are varied. Figures 5 and 6 present graphically the results from Tables 2 and 3, whereas Figures 7 and 8 do the same for Table 4. The main objective is to assess the consequences of balance sheet effects and the financial accelerator rigorously, when the economy is exposed to all three shocks simultaneously. ${ }^{12}$

\section{Perfect Capital Markets}

Table 2 considers the case with and without the financial accelerator channel present. Initially we focus on the comparison between a standard fixed exchange rate regime, column [1], and a flexible regime, column [2], where the central bank strictly targets the inflation rate. In the first two columns the financial accelerator channel is not present. Most of the previous literature that performs welfare comparisons uses a linearized version of the model, and their analysis is based only on the variances of consumption and labor to obtain welfare ranking. ${ }^{13}$ This is equivalent to comparing the variance metric, $\xi^{\text {variance }}$, of the peg with that of the float. Since the volatility of consumption and labor is higher under the peg than it is under the float, the welfare measure that uses only the variances is lower under the peg. The welfare loss, calculated as a percentage of steady-state consumption, is -0.237 under the peg and -0.102 under the float. The higher levels of macroeconomic volatility associated with the peg are undesirable and thus imply a larger welfare cost. Since the welfare losses associated with the float are lower when utilizing the variance metric, the literature states that this finding is consistent with the Mundell-Fleming framework, which highlights that the exchange rate acts as a shock absorber and thus can insulate the economy against external shocks more effectively. The standard policy recommendation that follows is that small open economies that are susceptible to destabilizing external disturbances should implement a float whereby the nominal exchange rate acts as a shock absorber.

When the appropriate welfare metric, $\xi$, is used, the fixed exchange rate regime is still welfare inferior to the floating regime. The overall welfare metric now accounts for the impact of the mean levels of consumption and labor, captured by the term, $\xi^{\text {mean }}$. Notice that since the welfare criterion is denoted in percentages, $\xi=\xi^{\text {mean }}+\xi^{\text {variance }}$. It is easy to see how our framework

12 Kollman (2002) investigates the consequences of exchange rate regimes on small open economies using the Sims (2000) method as well. However, he does not consider balance sheet effects and the implications of the financial accelerator channel.

13 See for example, Schmitt-Grohe and Uribe (2001), Devereux and Lane (2003), and Elekdag (2003). 
can better capture the effect of risk on the behavior of economic agents. The peg is relatively better suited to reduce exchange rate uncertainty and that is why the mean level of consumption increases by more than under the float. Individuals can also enjoy more leisure. $\xi^{\text {mean }}$ is therefore higher under the fixed exchange rate.

\section{The Financial Accelerator}

We now consider the welfare implications of various debt levels under different monetary policy regimes when balance sheet effects are present. We gradually increase the probability of business failure which implies a higher risk premium and debt-to-GDP ratio. This process enhances the vulnerability of the economy to exchange rate fluctuations and makes the flexible exchange rate regime less desirable. Table 2, columns [3]-[6], presents two summary cases that consider the impact of capital market frictions.

First consider columns [5] and [6], corresponding to a case with a debt-to-GDP ratio of approximately 31 percent. If welfare comparisons were conducted incorrectly using a first-order approximation, this is the threshold where the monetary authority is indifferent between whether a fixed or floating exchange rate regime is implemented. This is because the welfare costs using the spurious metric ( $\xi^{\text {variance }}$ ) is -0.208 for both regimes. In other words, using this inaccurate measure of welfare, one would conclude that implementing a float dominates a peg until a debt-to-GDP ratio of approximately 31 percent. In fact, this threshold is very similar to what Cespedes, Chang, and Velasco (2002) find. However, they state that only an extreme calibration of their model would yield such a high debt-to-GDP ratio and therefore implicitly discount any merits the fixed exchange rate regime may offer. ${ }^{14}$

Now we consider columns [3] and [4] where the debt-to-GDP ratio is equal to 16 percent. This is the case where the small open economy is indifferent between the peg and the float using the accurate welfare metric $(\xi)$, which is -0.238 . Notice that there exists a clear trade-off between the lower volatility under the flexible exchange rate regime and enhanced mean gains from the fixed regime. While it is still the case that the standard deviations of consumption, labor, and output are lower under float, the peg delivers a higher mean level of consumption and a lower increase in labor effort. Relatedly, the peg successfully insulates the economy from effects that could destabilize net worth and risk premium substantially. This stems from the fact that the peg eliminates currency risk due to potentially severe currency mismatches.

It is crucial to underscore that incorrectly using a first-order approximation in our framework would still imply that float is better than fixed as exemplified by the comparison of $\xi^{\text {variance }}(-0.24$ for a peg and -0.098 for a float) when the debt-to-GDP level is 16 percent. Focusing only on the variance metric, $\xi^{\text {variance }}$, the strict inflation targeting regime seems to be less costly relative to the peg. Notice that this measure does not change very much whether balance sheet effects are present or not. The true impact of the financial accelerator is highlighted when the appropriate welfare measure is used and when the mean effects are taken into consideration. Hence, we provide

14 See Cespedes, Chang, and Velasco (2002), page 33. 
evidence that fixed exchange rate regimes could potentially enhance credibility and enhance welfare relative to the float. For levels of debt-to-GDP beyond 16 percent the fixed exchange rate welfare dominates the flexible exchange rate.

The main message of previous research dealing with the financial accelerator is that the calibration necessary to introduce such a case is extreme and falls out of the scope of reasonable parameter values. Our results clearly point out that the past literature has disregarded the potential benefits that fixed exchange rate may deliver on the mean levels of consumption and output and has overemphasized the gains associated with the expenditure-switching effects of flexible regimes. An important consequence of our analysis is that in the presence of capital market frictions the debt-to-GDP ratio that triggers a situation where peg is welfare superior occurs at levels of indebtedness almost two times lower that those cited by Cespedes, Chang, and Velasco (2002).

Table 3 provides more cases for a wider variety of debt-to-GDP ratios. It is obvious now that for threshold values of below 16 percent, flexible exchange rate is better and for levels of above 16 percent, fixed exchange rate dominates if one uses the proper welfare metric. Peg is inferior for threshold level of below 31 percent if a first-order approximation is used and it delivers a better welfare performance for values higher than that.

Figures 5 and 6 present our main welfare results graphically. Figure 6 depicts the case when the accurate welfare metric is employed and exhibits a monotonic decrease in welfare for both fixed and flexible exchange rate regimes with a breakeven point of 16 percent. To reinforce one the main contributions of the paper, above this threshold level of 16 percent, the rigorous welfare metric indicates that the peg dominates the float. Whereas, Figure 5, which depicts the incorrect welfare measure, indicates that only after the debt-to-GDP level exceeds 31 percent does the flexible exchange rate become inferior. Figure 5 seems to demonstrate that for a certain range of debt-to-GDP ratios there exists a nonlinearity in the welfare generated under a flexible exchange rate. There are two possible explanations for that. First, if we use the usual ad-hoc welfare metric that is quadratic in the output and inflation, we will see that welfare is monotonically decreasing in the debt-to-GDP ratio. Since inflation is targeted under a float, its volatility is zero, but the standard deviation of output increases with the level of indebtedness. This is just another reason why welfare comparisons based on ad-hoc metrics are misleading. Another reason is that for certain debt levels the expenditure-switching effect of flexible exchange rate may dominate the opposing effect of devaluations associated with the balance sheet effects. In any case, such results only seem to underline the potential pitfalls in trying to conduct spurious welfare comparisons and reinforce our contention that advancing policy recommendations may be misleading if one is resorting to linear approximations when higher-order approximations are necessary.

Table 4 changes the benchmark calibration in that it keeps the steady-state level of the risk premium constant. Figure 7 graphs the evolution of the EMBI index since its inception. This index represents the interest rate spread of emerging market countries' dollar-denominated debt over US Treasury bonds of similar maturity. In effect, this spread may be interpreted as the risk premium associated with borrowing abroad controlling for maturity mismatches and currency risk. Its average is 7.79 percent and we calibrate the steady-state solution of the model such that 
the steady state risk premium is equal to 8 percent by choosing an appropriate probability of business failure. Simultaneously, the elasticity of the risk premium with respect to the capital to net worth ratio changes to achieve different debt-to-GDP ratios.

The general thrust of the results do not change. Fixed exchange rate is better than flexible exchange rate for levels of indebtedness higher than 21 percent if welfare is based on the volatility of consumption and labor. When the proper metric is employed, the threshold valued reduces to 31 percent.

Figures 8 and 9 graph the welfare costs of these alternative regimes for more debt-to-GDP ratios using first- and second-order approximations.

\section{Robustness Analysis}

Table 5 discusses an array of additional experiments that help check the sensitivity of the model to important model parameters and different interest rate rules. In particular, we investigate if the strict inflation-targeting rule is somewhat inferior in that it does not help stabilize output and nominal exchange rate depreciation. Moreover, we examine cases where the intratemporal elasticity of substitution is lower as this, according to Cespedes, Chang, and Velasco (2002), should make the effect of the financial accelerator more potent. In addition, we explore a calibration where we increase the openness of the home economy.

\section{Alternative Monetary Policy Rules}

Table 5 includes two alternative regimes. We consider the popular Taylor rule and what we dub the Augmented Taylor rule (ATR) which explicitly considers exchange rate movements. The peg and strict inflation-targeting regimes are shown under columns [1] and [2], and the ones with the Taylor rule and the ATR under columns [3] and [4]. Comparing the variance component of welfare, $\xi^{\text {variance }}$, the strict inflation targeting rule is still the best, while the augmented Taylor rule follows. Considering the appropriate welfare measure, $\xi$, both Taylor type rules yield higher welfare than the strict inflation-targeting regimes. However, they are still inferior to the peg.

While it is true that considering more flexible interest rules does not change the overall welfare ranking of exchange rate regimes, we should be cautious in arguing that peg is always better than float. There are countless ways to implement a floating exchange rate. The true insight of the Mumdell-Fleming framework stipulates that a flexible exchange rate regime is better than the peg if it can optimally accommodate the impact of external shocks. Hence we recognize that the proper exercise would be to compare the peg with the welfare maximizing optimal exchange rate regime. At the same time, to the extent that such optimal policy is difficult to uncover and especially implement in emerging market economies, a simple policy of fixing the nominal exchange rate or its depreciation rate may be quite attractive in countries that suffer from significant levels of dollar denominated liabilities and insufficient institutional capacity.

Cespedes, Chang, and Velasco (2002) argue that in a model with a Cobb-Douglas specification

of the consumption index, the behavior of the risk premium is independent of exchange rate and 
monetary regime. However, if the elasticity of substitution between home and foreign goods is lower than one, a real devaluation increases the risk premium and implies greater financial fragility, which might make the peg better than the float. We also consider such an extension by postulating a CES consumption index with an intratemporal elasticity of substitution of $\theta$ :

$$
C_{t}^{1-\theta}=\gamma C_{H t}^{1-\theta}+(1-\gamma) C_{F t}^{1-\theta}
$$

We set $\theta$ to its lowest possible value of zero and examine the welfare results in columns [5] to [8]. When we use a first-order approximation, the breakeven point beyond which peg dominates drops to 26 percent. The steady-state risk premium in this case is 6.2 percent and is actually is lower than the one when $\theta=1$. Moreover, the welfare loss is bigger with a Cobb-Douglas specification. Only when we conduct the welfare analysis using a second-order approximation, do we show that the risk premium relative to the case with $\theta=1$ increases from 1.39 to 3.09 percent and the welfare loss is twice as high as from -0.238 to -0.486 percentage points of steady state consumption.

Finally, we increase the openness of the home economy and set $\gamma=0.65$. Columns [9] to [12] show the results from this exercise. As expected, welfare loss increases substantially for the threshold values where peg becomes welfare superior to float. When $\gamma=0.75, \xi=-0.238$ and when $\gamma=0.65, \xi=-1.507$.

\section{CONCLUding Remarks}

We developed a small open-economy model with financial frictions and analyzed rigorously the welfare implications of fixed and flexible exchange rate regimes. We confirmed that the flexible exchange rate has better welfare properties than the fixed exchange rate in an economy without financial frictions. We found that the presence of a financial accelerator mechanism reduces welfare relative to an economy without financial frictions.

Most importantly, we uncovered threshold values of the debt-to-GDP ratios beyond which a peg dominates a float. When the model with the financial accelerator is solved using linear methods this level of indebtedness is around 31 percent. We underlined that the linear-quadratic approach in an environment with sticky prices, monopolistic competition, and imperfect financial markets delivers spurious and misleading welfare rankings. However, when we utilize a full second-order expansion of the model in order to take into account the effect of risk on the behavior of the economic agents, we find that the threshold is 16 percent. For levels of indebtedness above 16 percent, the fixed exchange rate enjoys a credibility advantage and delivers a smaller increase in the risk premium. This stunts investment to a lesser extent implying milder recessions.

Previous literature has contended that the superiority of the peg over a float can be simulated only under extreme calibrations. Moreover, the comparison between exchange rate regimes has been mostly confined to calculating impulse response functions. We have demonstrated that if one conducts an accurate welfare examination of alternative exchange rate regimes, one does not need 
to resort to unreasonable parameter values to come up with a case where peg is welfare superior. In fact, in our view, one can simulate such cases for a wide range of calibrated models.

These results do not, however, imply that fixed exchange rates are universally superior to flexible exchange rates. It is possible that an optimal monetary policy rule that entails a high degree of exchange rate flexibility may yield higher welfare than a peg even for debt-to-GDP ratios of above 16 percent. In this sense, our analysis should not be viewed as an attempt to change the conventional policy recommendations prescribed by the Mundell-Fleming model.

Our results offer insight on the behavior of authorities in emerging market economies that face balance sheet effects and provides some theoretical justification for the "Fear of Floating" argument advanced by Calvo and Reinhart (2001). The risk premium associated with borrowing abroad in dollars is a crucial determinant for the choice of an appropriate exchange rate regime. While it could be optimal for such countries to pursue policies implying a flexible exchange rate, such policies may be difficult to achieve due to weak institutional infrastructure. From that perspective, a fixed exchange rate may be more desirable than standard interest rate rules that allow pronounced nominal exchange rate flexibility. 
Table 1. Parameter Calibration

\begin{tabular}{|l|l|l|}
\hline Parameter & Value & Description \\
\hline$\alpha$ & 0.35 & Share of $K$ in $Y$ \\
\hline$\beta$ & 0.99 & Subjective discount factor \\
\hline$\gamma$ & 0.75 & Share of $C_{H}$ in $C$ \\
\hline$\vartheta_{i^{*}}$ & 0.75 & Persistence of $i^{*}$ shock \\
\hline$\vartheta_{A}$ & 0.9 & Persistence of $A$ shock \\
\hline$\vartheta_{X}$ & 0.5 & Persistence of $X$ shock \\
\hline $\operatorname{var}\left(\varepsilon_{i^{*}}\right)$ & $0.004^{2}$ & Variance of $i^{*}$ shock \\
\hline $\operatorname{var}\left(\varepsilon_{A}\right)$ & $0.01^{2}$ & Variance of $A$ shock \\
\hline $\operatorname{var}\left(\varepsilon_{X}\right)$ & $0.08^{2}$ & Variance of $X$ shock \\
\hline$\lambda$ & 10 & Substitution elasticity between $C_{H j}$ \\
\hline$\sigma$ & 4 & Inverse substitution elasticity for $C$ \\
\hline$\phi_{B}$ & 0 & Adjustment cost for $B$ \\
\hline$\phi_{F^{*}}$ & 0.0019 & Adjustment cost for $F^{*}$ \\
\hline$\varphi$ & 200 & Adjustment cost for $P$ \\
\hline$\chi$ & 1 & Weight of $L$ in utility \\
\hline$\psi$ & 1 & Inverse substitution elasticity for $L$ \\
\hline
\end{tabular}


Table 2: Regime Comparison

\begin{tabular}{|c|c|c|c|c|c|c|}
\hline \multicolumn{3}{|c|}{ No Financial Accelerator } & \multicolumn{4}{|c|}{ Financial Accelerator Present } \\
\hline & \multicolumn{2}{|c|}{$\begin{array}{c}\text { Debt-to-GDP } \\
\text { ratio }\end{array}$} & \multicolumn{2}{|c|}{$16 \%$} & \multicolumn{2}{|c|}{$31.30 \%$} \\
\hline Regime & Peg & Float & Peg & Float & Peg & Float \\
\hline & {$[1]$} & {$[2]$} & [3] & [4] & [5] & [6] \\
\hline \multicolumn{7}{|c|}{ Means (\%) } \\
\hline $\mathbf{C}$ & 0.06 & 0.01 & 0.02 & -0.04 & -9.67 & -24.70 \\
\hline $\mathbf{L}$ & -0.05 & 0.03 & 0.02 & 0.11 & 14.72 & 37.28 \\
\hline $\mathbf{Y}$ & 0.02 & 0.06 & 0.04 & 0.07 & -2.14 & -6.27 \\
\hline $\mathbf{K}$ & 0.15 & 0.11 & 0.08 & 0.00 & -33.47 & -87.14 \\
\hline $\mathbf{S}$ & -0.34 & -0.09 & -0.23 & 0.05 & 21.23 & 53.96 \\
\hline INFL & 0.00 & 0.00 & 0.00 & 0.00 & -0.01 & 0.00 \\
\hline NW & 0.02 & -0.02 & -2.45 & -4.11 & -1240.14 & -3216.86 \\
\hline$\eta$ & 0.00 & 0.00 & 0.05 & 0.08 & 25.43 & 67.27 \\
\hline$\underline{\mathbf{D}}$ & 0.38 & 0.13 & -0.31 & -0.03 & -35.31 & -90.07 \\
\hline \multicolumn{7}{|c|}{ Standard Deviations (\%) } \\
\hline$\overline{\mathbf{C}}$ & 2.52 & 1.68 & 2.51 & 1.64 & 2.25 & 2.66 \\
\hline $\mathbf{L}$ & 5.05 & 3.25 & 5.08 & 3.21 & 4.99 & 3.92 \\
\hline $\mathbf{Y}$ & 3.13 & 2.29 & 3.24 & 2.34 & 5.75 & 5.11 \\
\hline $\mathbf{K}$ & 1.36 & 1.37 & 1.51 & 1.49 & 10.41 & 15.73 \\
\hline $\mathbf{S}$ & 7.08 & 4.01 & 7.08 & 3.92 & 7.11 & 5.17 \\
\hline INFL & 0.87 & 0.00 & 0.91 & 0.00 & 1.46 & 0.00 \\
\hline NW & 0.96 & 1.25 & 19.40 & 21.34 & 357.95 & 568.63 \\
\hline$\eta$ & 0.00 & 0.00 & 0.35 & 0.41 & 7.42 & 11.86 \\
\hline D & 8.75 & 6.53 & 21.02 & 21.40 & 7.57 & 4.33 \\
\hline
\end{tabular}

Welfare Loss (\% of ss consumption)

\begin{tabular}{lrlrrrr}
\hline$\xi^{\text {variance }}$ & -0.237 & -0.102 & -0.240 & -0.098 & $\mathbf{- 0 . 2 0 8}$ & $\mathbf{- 0 . 2 0 8}$ \\
$\xi^{\text {mean }}$ & 0.097 & -0.024 & 0.002 & -0.141 & -15.761 & -28.277 \\
$\xi^{-0.141}$ & -0.125 & $\mathbf{- 0 . 2 3 8}$ & $\mathbf{- 0 . 2 3 8}$ & -15.866 & -28.332 \\
\hline
\end{tabular}

Note: C denotes consumption, L labor, Y output, K capital, S real exchange rate, NW net worth, $\eta$ the risk premium and $\mathrm{D}$ debt. 
Table 3: Detailed Regime Comparison

Financial Accelerator Present

\begin{tabular}{|c|c|c|c|c|c|c|c|c|c|c|c|c|c|c|}
\hline Debt/GDP & \multicolumn{2}{|c|}{$1.70 \%$} & \multicolumn{2}{|c|}{$4.16 \%$} & \multicolumn{2}{|c|}{$12.70 \%$} & \multicolumn{2}{|c|}{$16 \%$} & \multicolumn{2}{|c|}{$24.37 \%$} & \multicolumn{2}{|c|}{$31.30 \%$} & \multicolumn{2}{|c|}{$31.35 \%$} \\
\hline Regime & Peg & Float & Peg & Float & Peg & Float & Peg & Float & Peg & Float & Peg & Float & Peg & Float \\
\hline & [1] & [2] & [3] & [4] & [5] & [6] & [7] & [8] & [9] & [10] & [11] & {$[12]$} & [13] & [14] \\
\hline
\end{tabular}

Means (\%)

\begin{tabular}{lrrrrrrrrrrrrrr}
\hline $\mathbf{C}$ & 0.03 & 0.00 & 0.04 & -0.01 & 0.04 & -0.02 & 0.02 & -0.04 & -0.04 & -0.14 & -9.67 & -24.70 & -12.81 & -35.30 \\
$\mathbf{L}$ & -0.03 & 0.06 & -0.02 & 0.07 & -0.01 & 0.07 & 0.02 & 0.11 & 0.12 & 0.26 & 14.72 & 37.28 & 19.46 & 53.21 \\
\hline
\end{tabular}

Standard Deviations (\%)

\begin{tabular}{|c|c|c|c|c|c|c|c|c|c|c|c|c|c|c|}
\hline $\bar{C}$ & 2.5 & 1.66 & 2.51 & 1.66 & 2.51 & 1.66 & 2.51 & 1.64 & 2.50 & 1.60 & 2.25 & 2.66 & 2.25 & 3.15 \\
\hline $\mathbf{L}$ & 5.05 & 3.22 & 5.06 & 3.22 & 5.06 & 3.22 & 5.08 & 3.21 & 5.09 & 3.17 & 4.99 & 3.92 & 4.99 & 4.46 \\
\hline
\end{tabular}

\section{Welfare Loss (\% of ss consumption)}

\begin{tabular}{lrlllllllllllll}
\hline$\xi^{\text {variance }}$ & -0.236 & -0.100 & -0.236 & -0.100 & -0.236 & -0.100 & -0.240 & -0.098 & -0.236 & -0.095 & $\mathbf{- 0 . 2 0 8}$ & $\mathbf{- 0 . 2 0 8}$ & -0.208 & -0.283 \\
$\xi^{\text {mean }}$ & 0.060 & -0.064 & 0.056 & -0.070 & 0.047 & -0.080 & 0.002 & -0.141 & -0.142 & -0.359 & -15.761 & -28.277 & -19.122 & -33.772 \\
$\xi^{-0.176}$ & -0.164 & -0.181 & -0.170 & -0.189 & -0.180 & $\mathbf{- 0 . 2 3 8}$ & $\mathbf{- 0 . 2 3 8}$ & -0.376 & -0.452 & -15.866 & -28.332 & -19.211 & -33.826 \\
\hline
\end{tabular}

Note: $\mathrm{C}$ denotes consumption and L labor. 
Table 4: Alternative Regime Comparison

\begin{tabular}{|c|c|c|c|c|c|c|c|c|c|c|c|c|c|c|}
\hline Debt/GDP & \multicolumn{2}{|c|}{$1.98 \%$} & \multicolumn{2}{|c|}{$4.00 \%$} & \multicolumn{2}{|c|}{$7.16 \%$} & \multicolumn{2}{|c|}{$21.00 \%$} & \multicolumn{2}{|c|}{$26.38 \%$} & \multicolumn{2}{|c|}{$31.02 \%$} & \multicolumn{2}{|c|}{$31.10 \%$} \\
\hline Regime & Peg & Float & Peg & Float & Peg & Float & Peg & Float & Peg & Float & Peg & Float & Peg & Float \\
\hline & {$[1]$} & {$[2]$} & [3] & [4] & {$[5]$} & [6] & [7] & {$[8]$} & [9] & {$[10]$} & [11] & {$[12]$} & [13] & {$[14]$} \\
\hline \multicolumn{15}{|l|}{ Means (\%) } \\
\hline$\overline{\mathbf{C}}$ & -0.04 & -0.06 & -0.05 & -0.06 & -0.06 & -0.08 & -0.07 & -0.14 & -0.34 & -0.62 & -9.42 & -24.41 & -11.50 & -31.34 \\
\hline $\mathbf{L}$ & 0.17 & 0.16 & 0.17 & 0.17 & 0.18 & 0.21 & 0.19 & 0.28 & 0.61 & 1.02 & 14.37 & 36.86 & 17.51 & 47.29 \\
\hline \multicolumn{15}{|c|}{ Standard Deviations (\%) } \\
\hline$\overline{\mathbf{C}}$ & 2.62 & 1.67 & 2.61 & 1.66 & 2.59 & 1.64 & 2.55 & 1.60 & 2.48 & 1.52 & 2.24 & 2.68 & 2.24 & 3.01 \\
\hline
\end{tabular}

\section{Welfare Loss (\% of ss consumption)}

\begin{tabular}{lllllllllllllll}
\hline$\xi^{\text {variance }}$ & -0.283 & -0.107 & -0.263 & -0.105 & -0.260 & -0.102 & -0.250 & -0.097 & -0.242 & -0.089 & $\mathbf{- 0 . 2 1 0}$ & $\mathbf{- 0 . 2 1 0}$ & -0.209 & -0.259 \\
$\xi^{\text {mean }}$ & -0.134 & -0.170 & -0.194 & -0.215 & -0.196 & -0.257 & -0.228 & -0.382 & -0.855 & -1.454 & -15.480 & -28.103 & -17.796 & -31.923 \\
$\xi$ & -0.427 & -0.277 & -0.455 & -0.319 & -0.456 & -0.359 & $\mathbf{- 0 . 4 7 7}$ & $\mathbf{- 0 . 4 7 7}$ & -1.088 & -1.537 & -15.587 & -28.160 & -17.892 & -31.979 \\
\hline
\end{tabular}

Note: C denotes consumption and L labor. 
Table 5: Comparisons with Other Regimes and Calibrations

Financial Accelerator Present

\begin{tabular}{|c|c|c|c|c|c|c|c|c|c|c|c|c|}
\hline \multirow[b]{2}{*}{ Debt/GDF } & \multirow[b]{3}{*}{ Peg } & \multirow{2}{*}{\multicolumn{2}{|c|}{$30.97 \%$}} & \multicolumn{5}{|c|}{$\begin{array}{l}\text { Less intratemporal elasticity } \\
\qquad \Theta=0\end{array}$} & \multicolumn{4}{|c|}{$\begin{array}{l}\text { Home economy more open } \\
\qquad \gamma=0.65\end{array}$} \\
\hline & & & & & 26.0 & $2 \%$ & 31.1 & $0 \%$ & 26.8 & $8 \%$ & 31.3 & $7 \%$ \\
\hline \multirow[t]{2}{*}{ Regime } & & Float & Taylor & ATR & Peg & Float & Peg & Float & Peg & Float & Peg & Float \\
\hline & {$[1]$} & {$[2]$} & [3] & [4] & {$[5]$} & [6] & [7] & {$[8]$} & [9] & {$[10]$} & {$[11]$} & [12] \\
\hline \multicolumn{13}{|c|}{ Means (\%) } \\
\hline $\mathbf{C}$ & -2.24 & -4.52 & -3.30 & -3.11 & -0.12 & -0.19 & -2.29 & -9.36 & -0.44 & -0.55 & -30.67 & -50.43 \\
\hline $\mathbf{L}$ & 3.48 & 6.89 & 4.70 & 4.68 & 0.26 & 0.28 & 3.62 & 14.02 & 0.85 & 0.99 & 46.63 & 76.22 \\
\hline \multicolumn{13}{|c|}{ Standard Deviations (\%) } \\
\hline C & 2.34 & 1.59 & 2.63 & 2.21 & 1.83 & 1.33 & 1.79 & 2.13 & 3.03 & 1.86 & 2.42 & 3.10 \\
\hline $\mathbf{L}$ & 5.05 & 3.00 & 4.99 & 4.41 & 4.13 & 2.28 & 4.15 & 3.29 & 6.73 & 4.25 & 6.33 & 4.74 \\
\hline \multicolumn{13}{|c|}{ Welfare Loss (\% of steady state consumption) } \\
\hline$\xi^{\text {variance }}$ & -0.219 & -0.089 & -0.245 & -0.181 & -0.141 & -0.058 & -0.138 & -0.138 & -0.376 & -0.147 & -0.289 & -0.289 \\
\hline$\xi^{\text {mean }}$ & -4.765 & -8.716 & -6.440 & -6.285 & -0.345 & -0.429 & -4.907 & -15.295 & -1.146 & -1.368 & -31.656 & -39.406 \\
\hline$\xi$ & -4.945 & -8.778 & -6.628 & -6.425 & -0.486 & -0.486 & -5.020 & -15.365 & -1.507 & -1.507 & -31.720 & -39.445 \\
\hline
\end{tabular}

Note: C denotes consumption and L labor. 
FIGURE 1: Negative Export Shock under a Peg (No Financial Accelerator) (In percent)
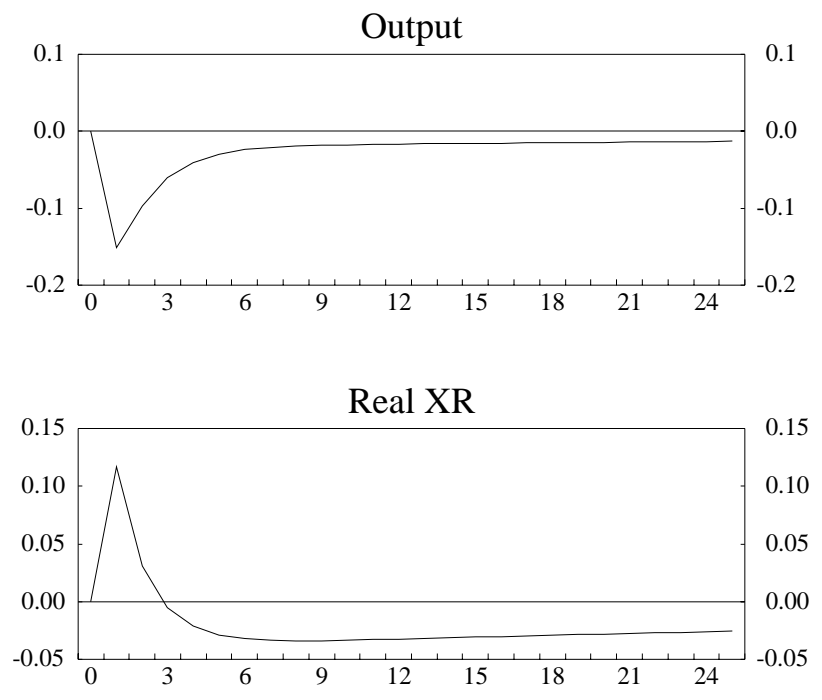

Labor

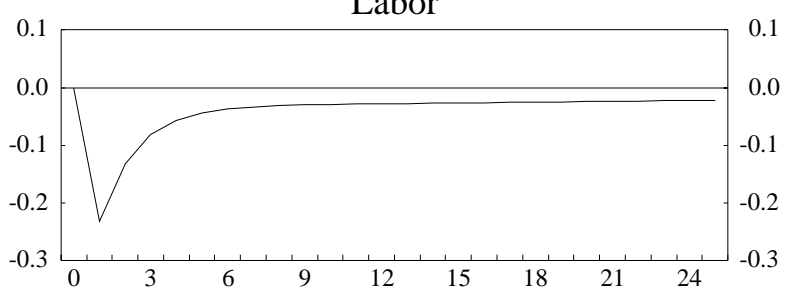

Risk Premium
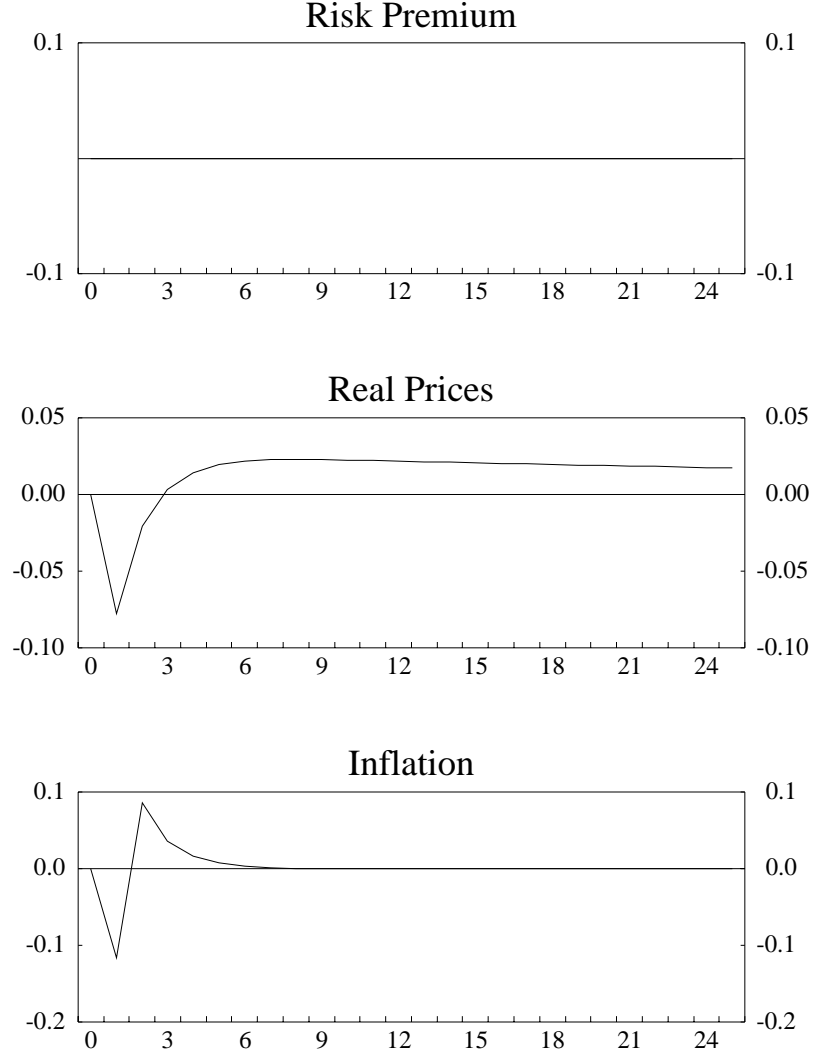
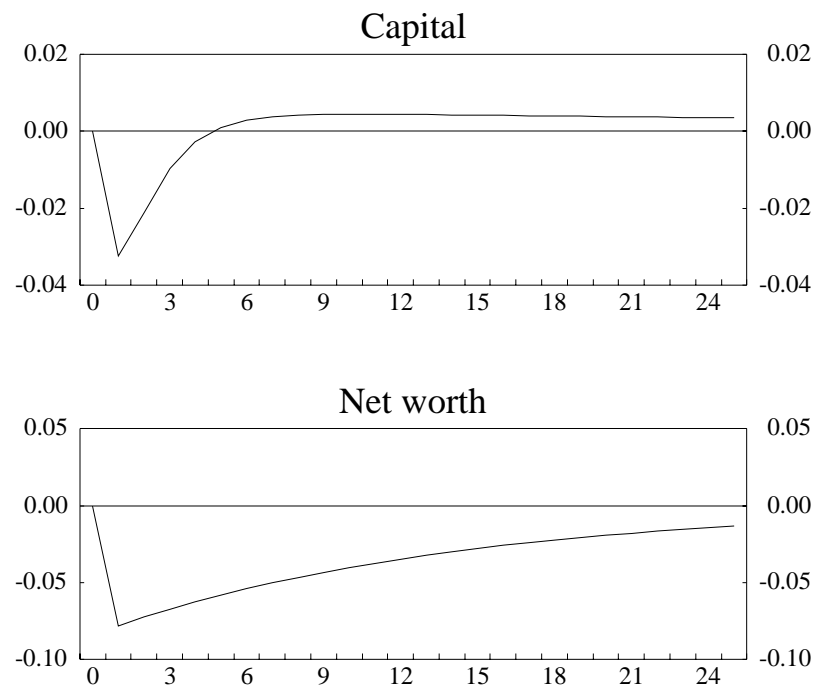

Debt
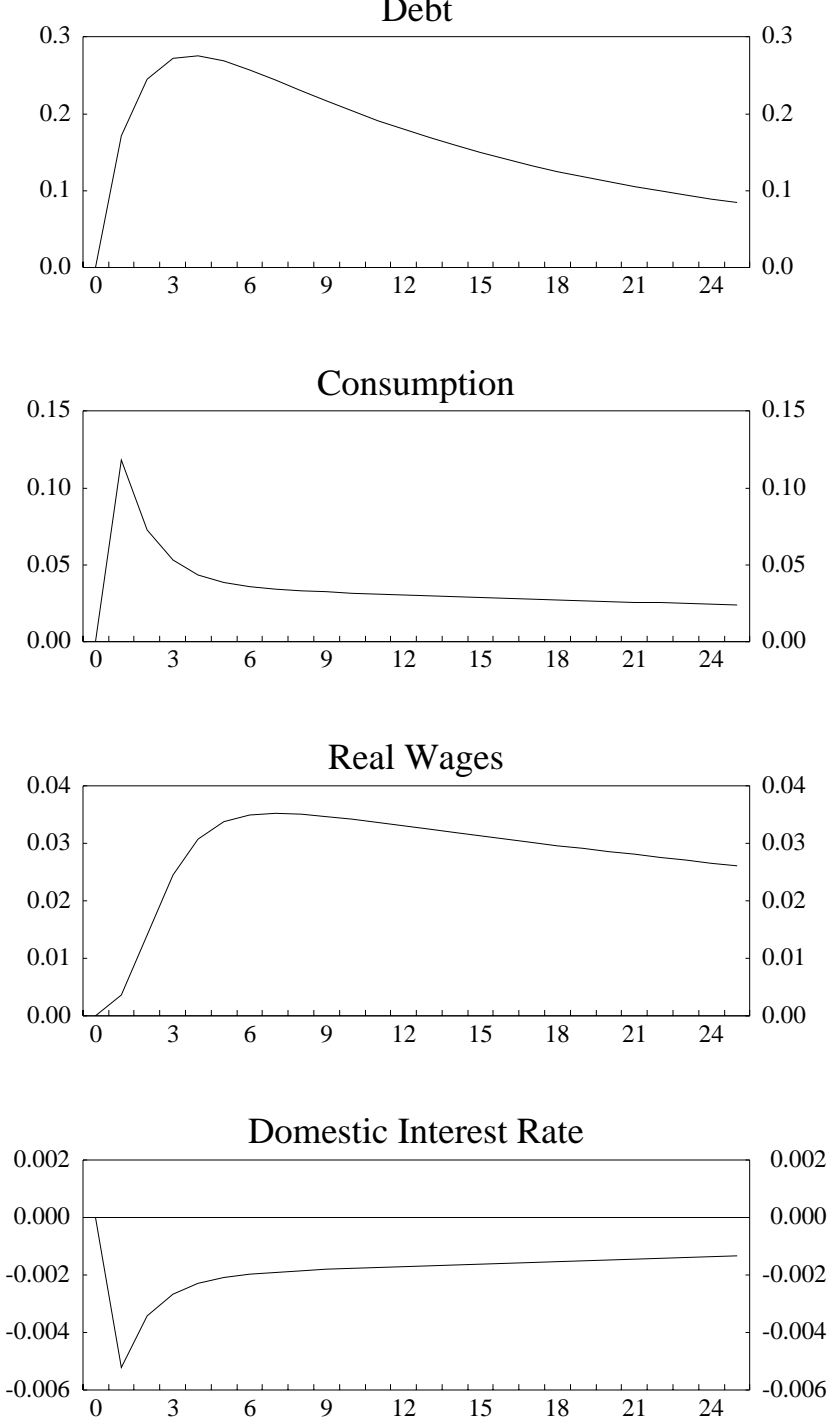
FIGURE 2: Negative Export Shock under a Float (No Financial Accelerator) (In percent)

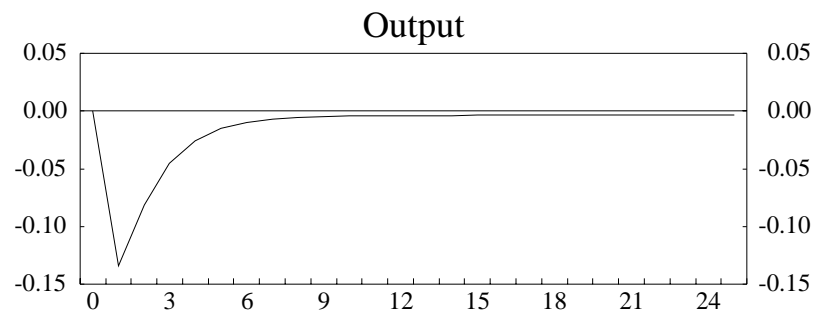

Real XR

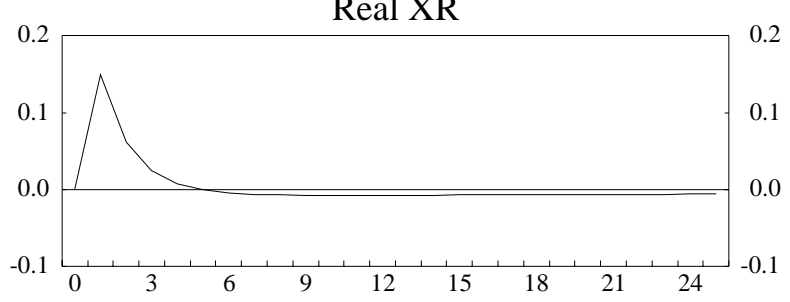

Labor

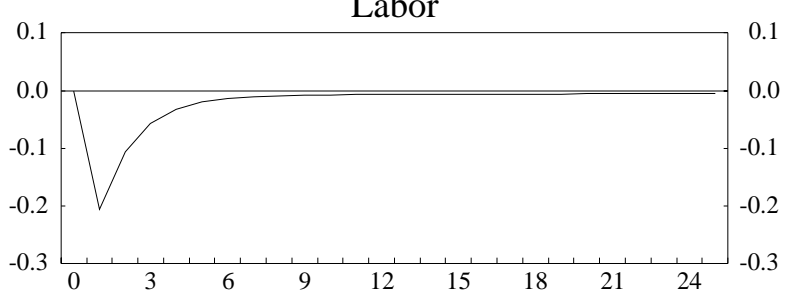

Risk Premium
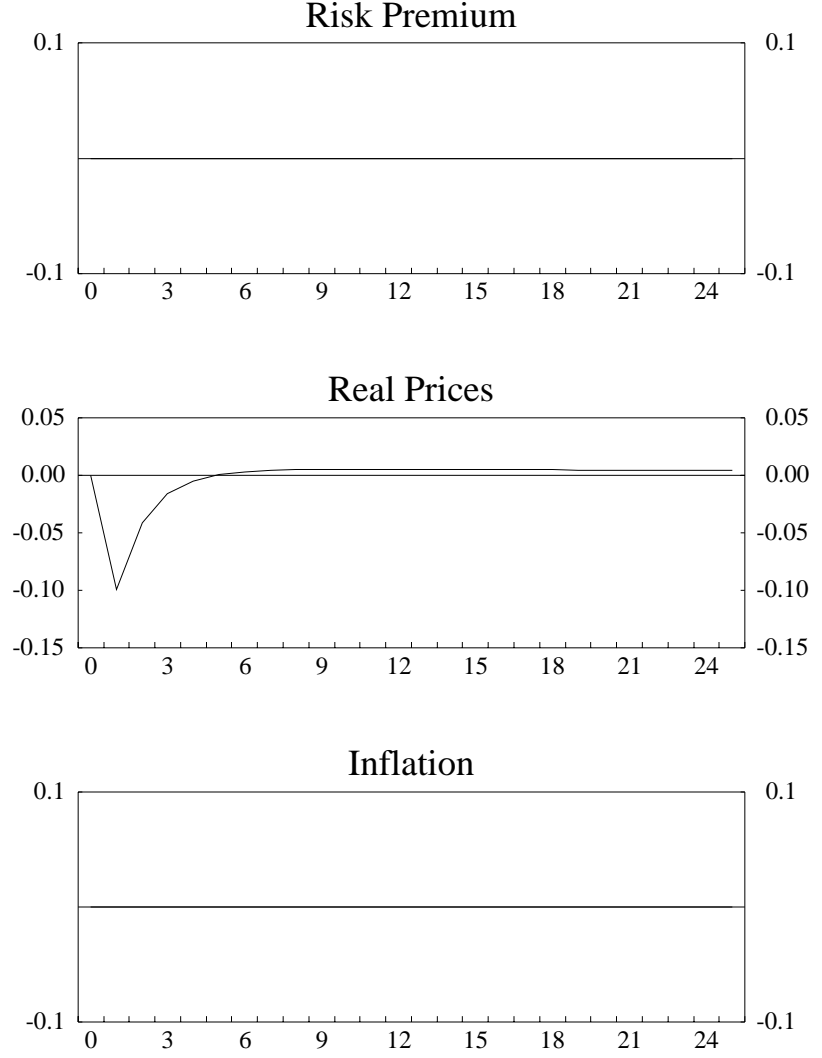
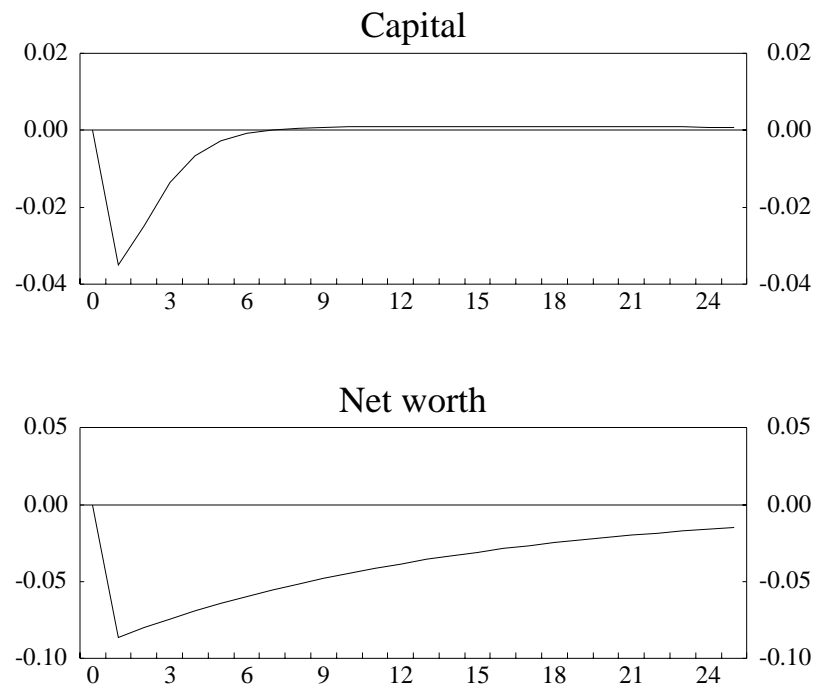

Debt
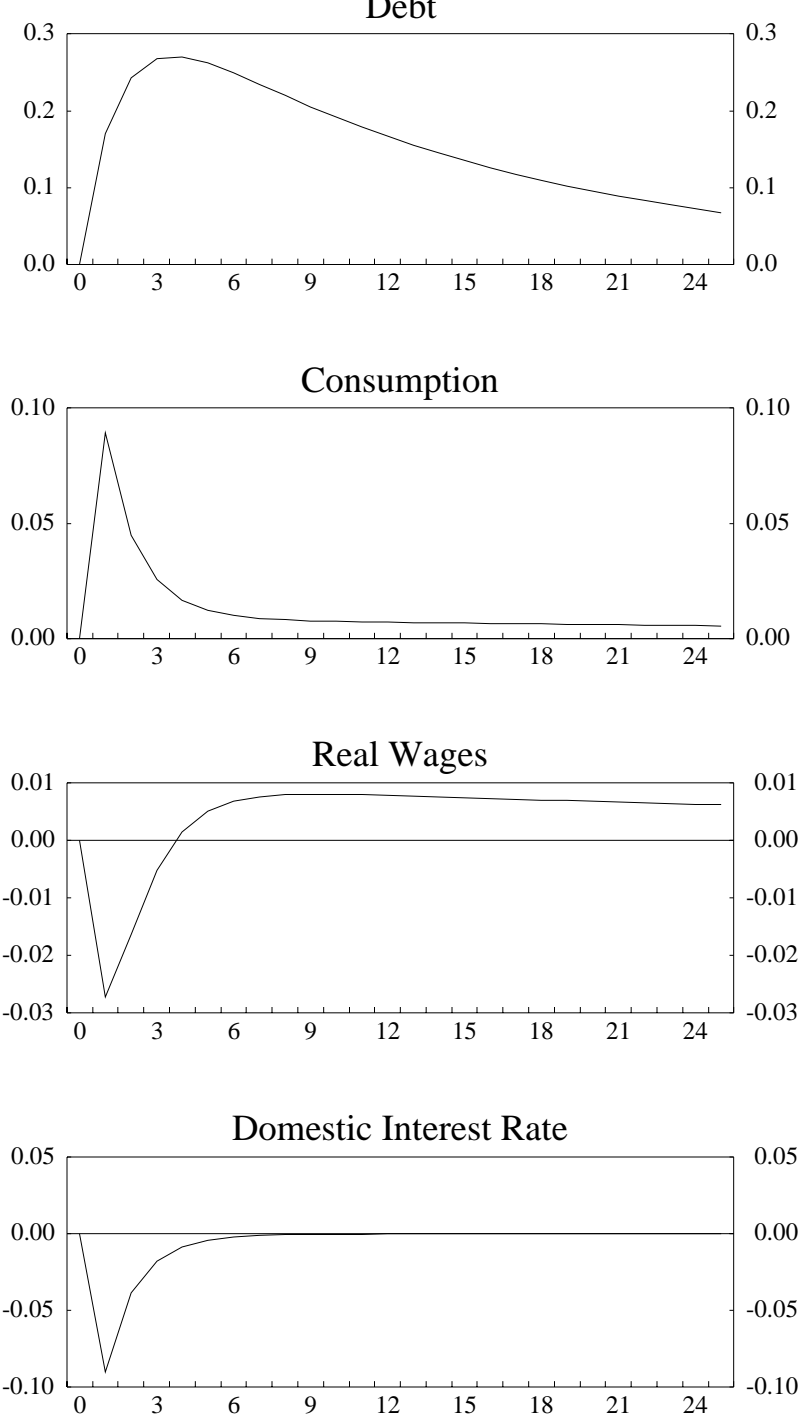
FIGURE 3: Negative Export Shock under a Peg (with Financial Accelerator) (In percent)

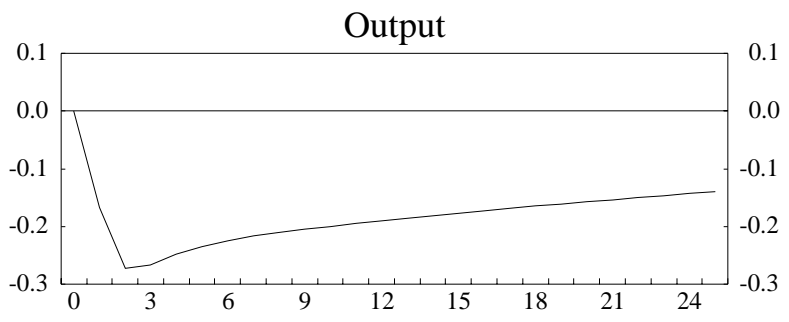

Real XR

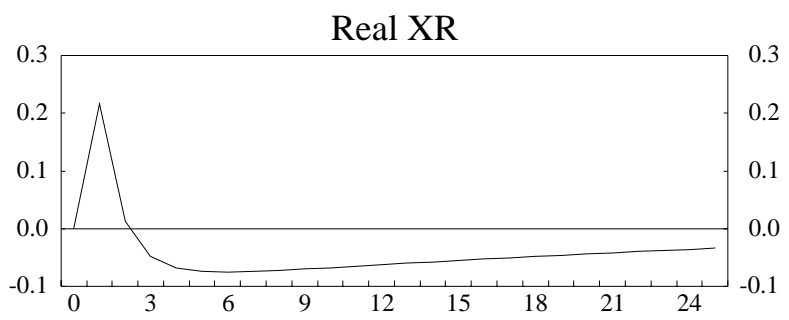

Labor

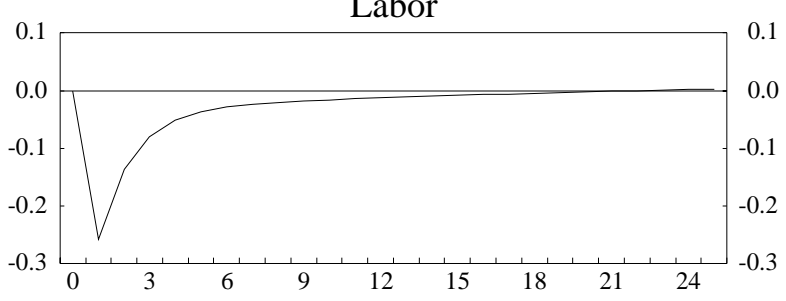

Risk Premium

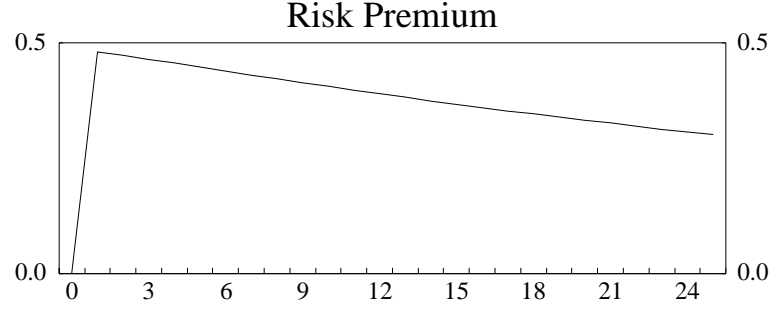

Real Prices

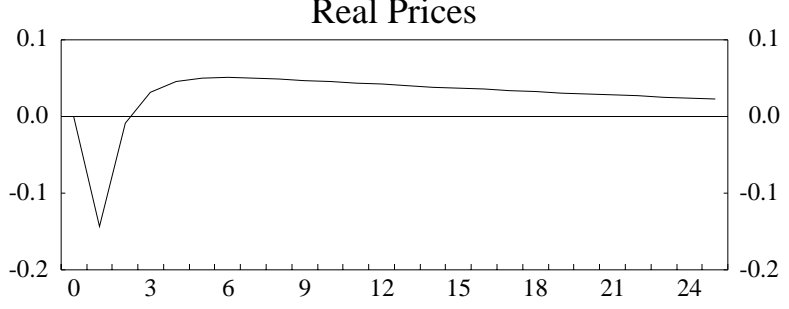

Inflation

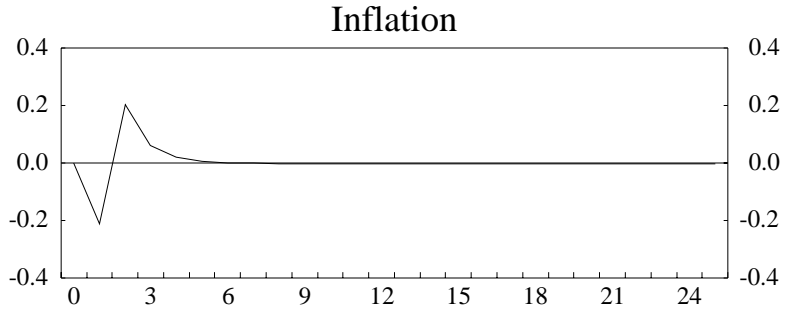

Capital

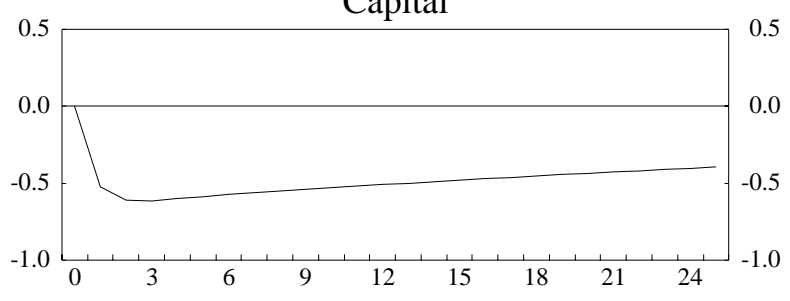

Net worth

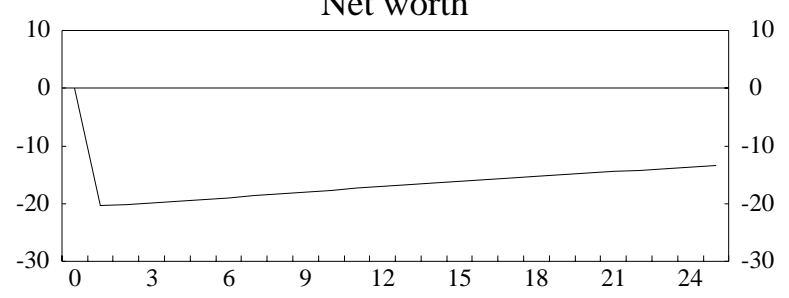

Debt
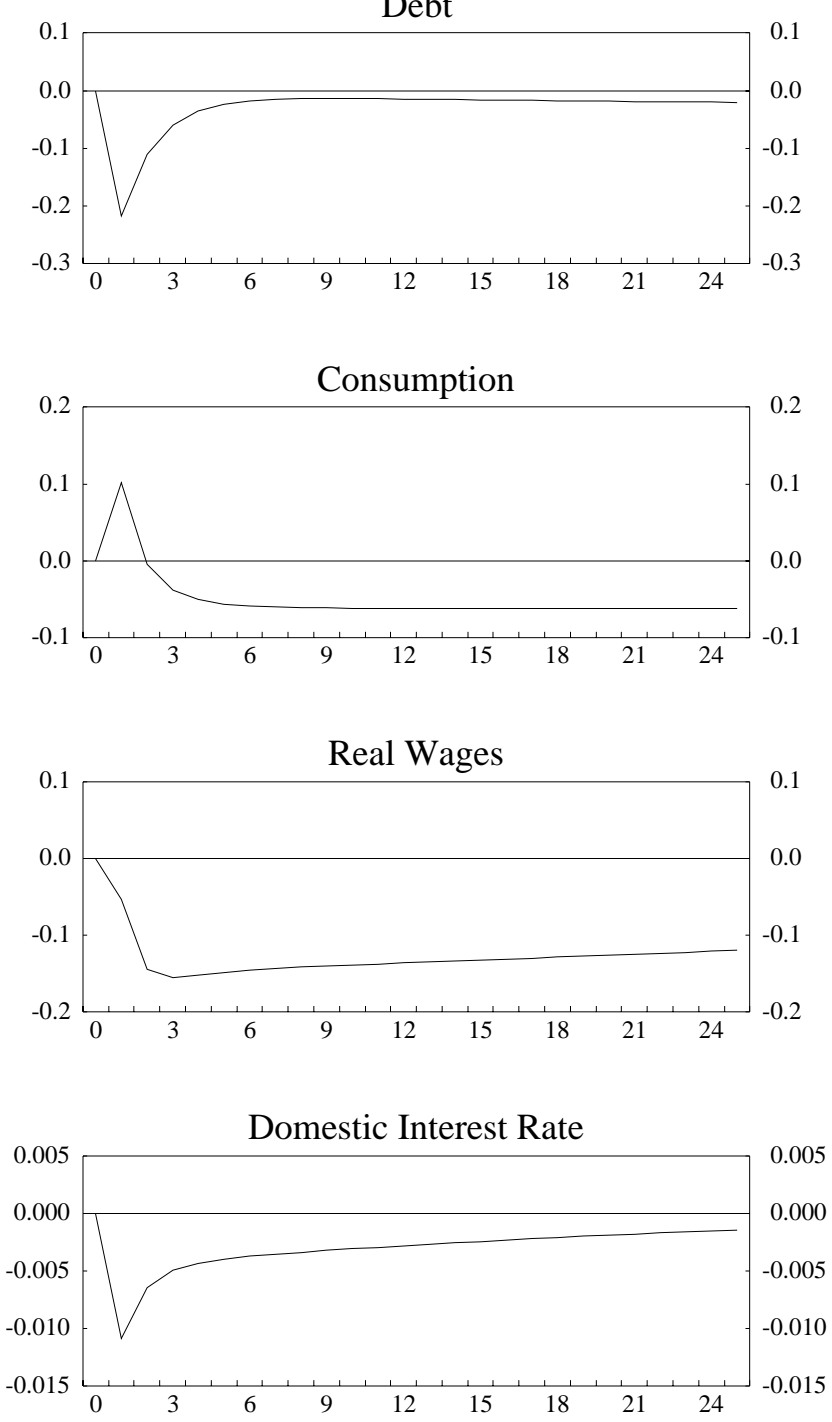
FIGURE 4: Negative Export Shock under a Float (with Financial Accelerator) (In percent)

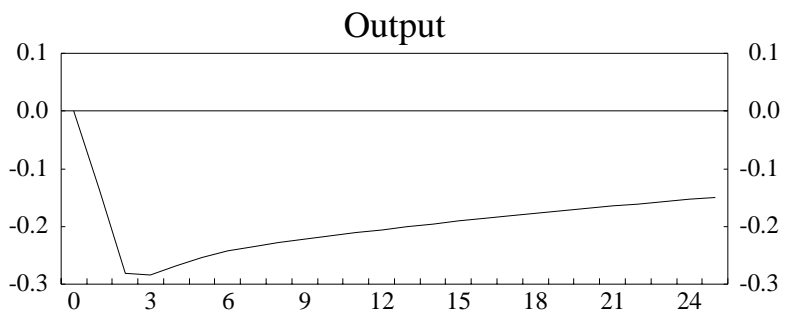

Real XR

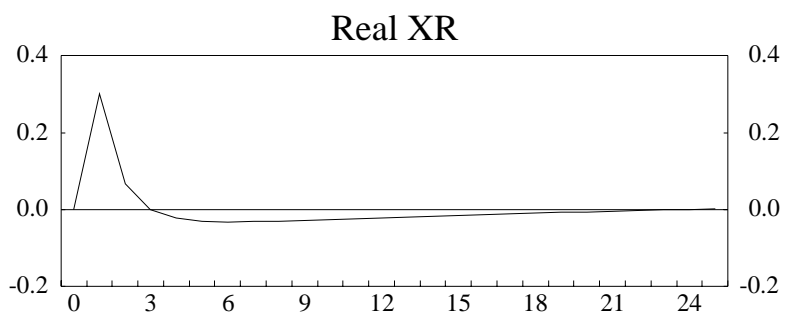

Labor

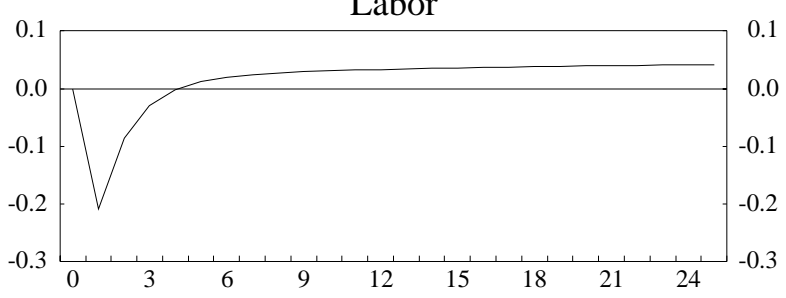

Risk Premium

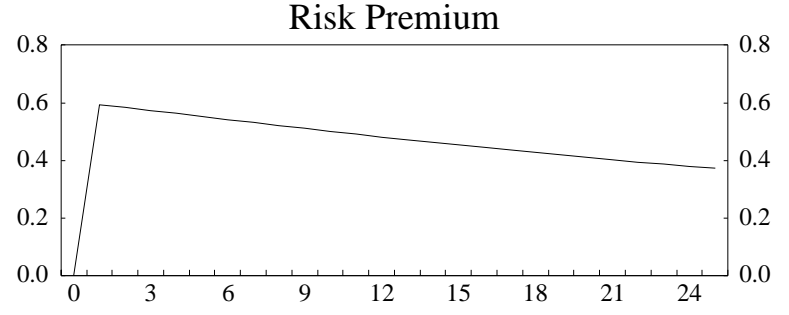

Real Prices

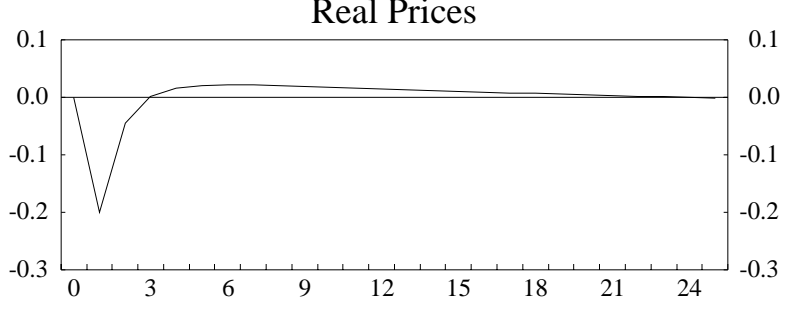

Inflation

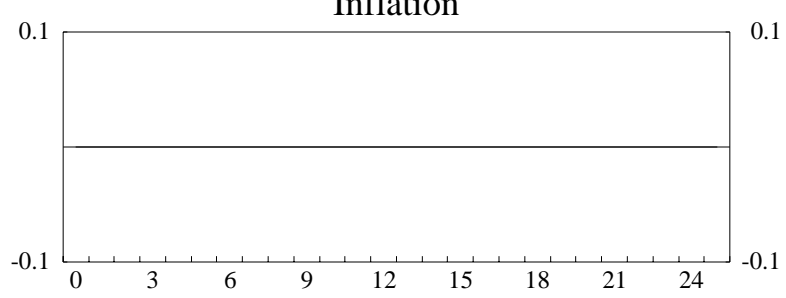

Capital

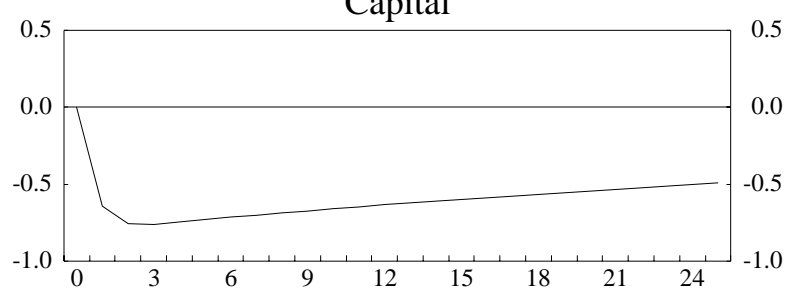

Net worth

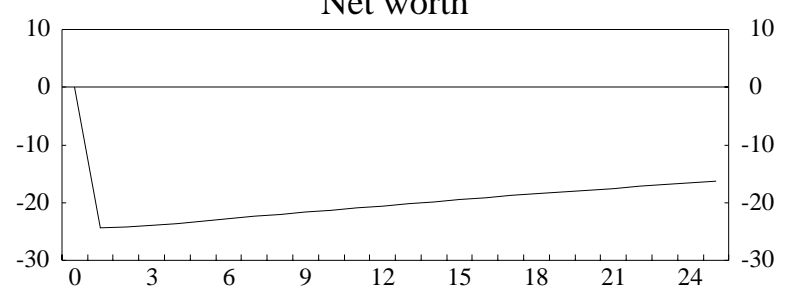

Debt
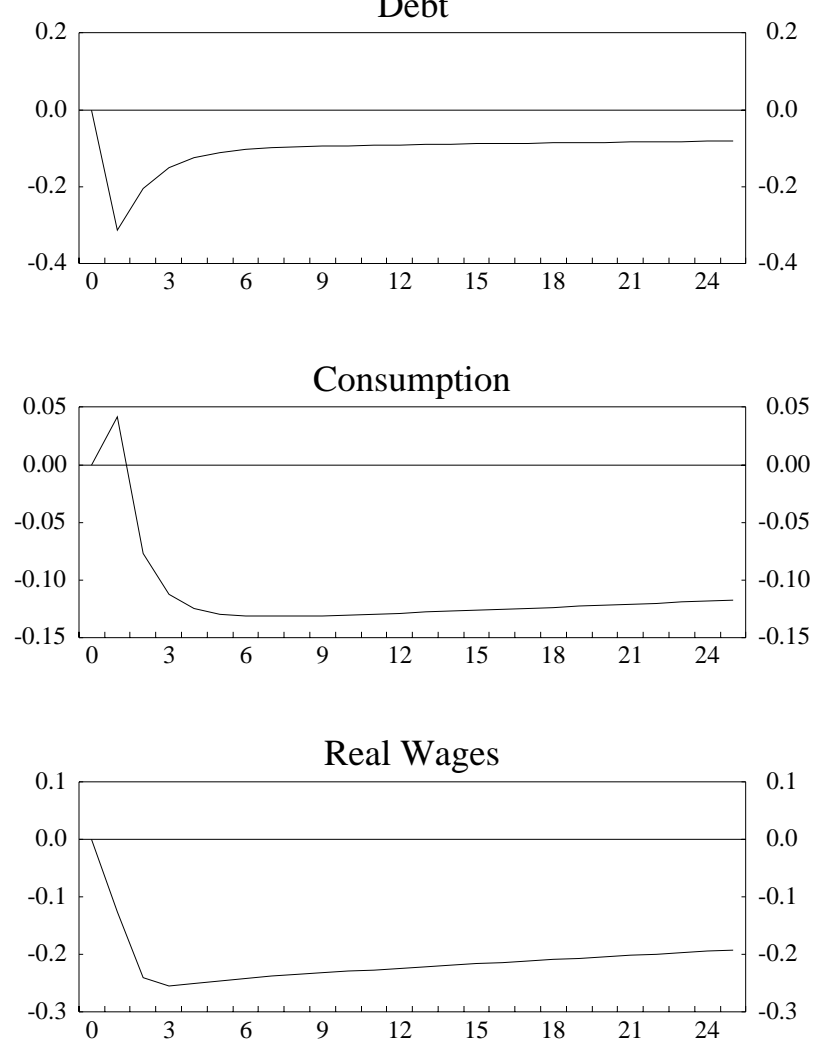

Domestic Interest Rate

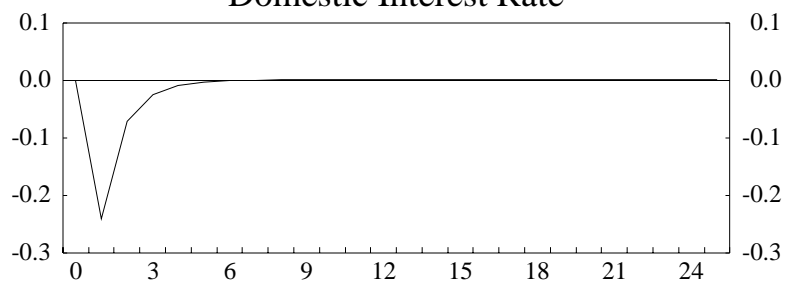


Figure 5: Welfare Comparison Using a First-Order Approximation

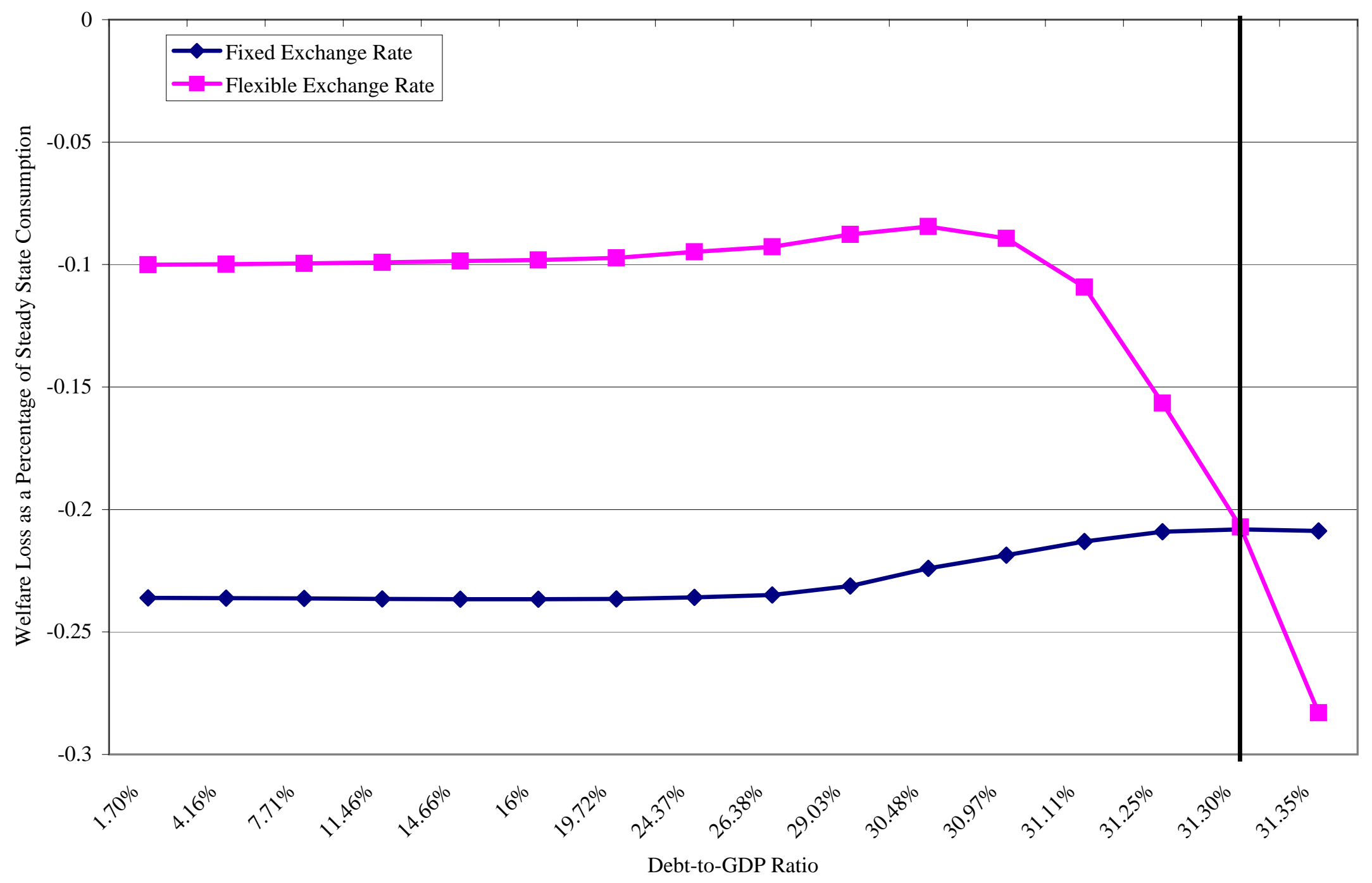


Figure 6: Welfare Comparison Using a Second-Order Approximation

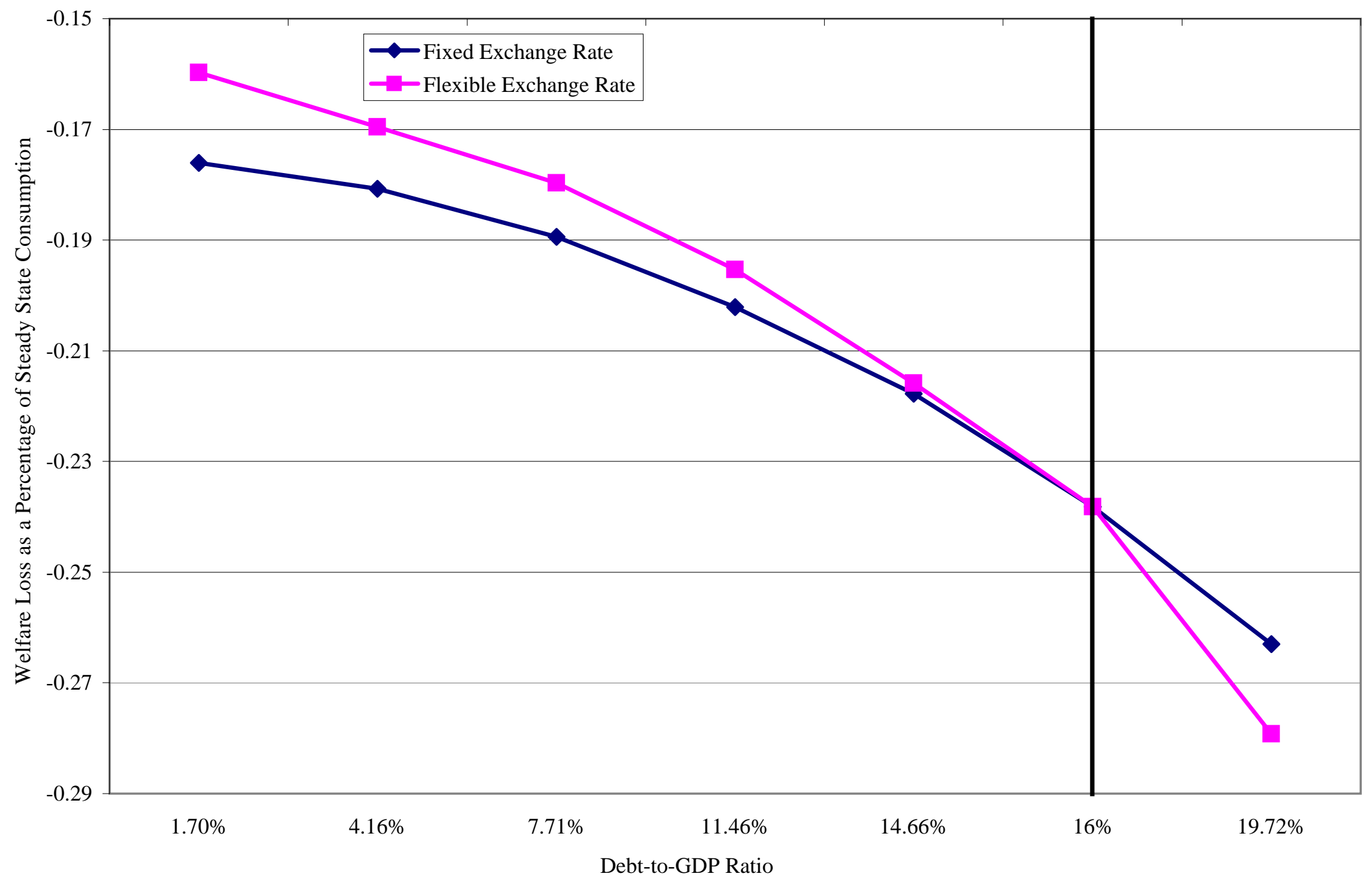


Figure 7: Emerging Markets Bonds Index

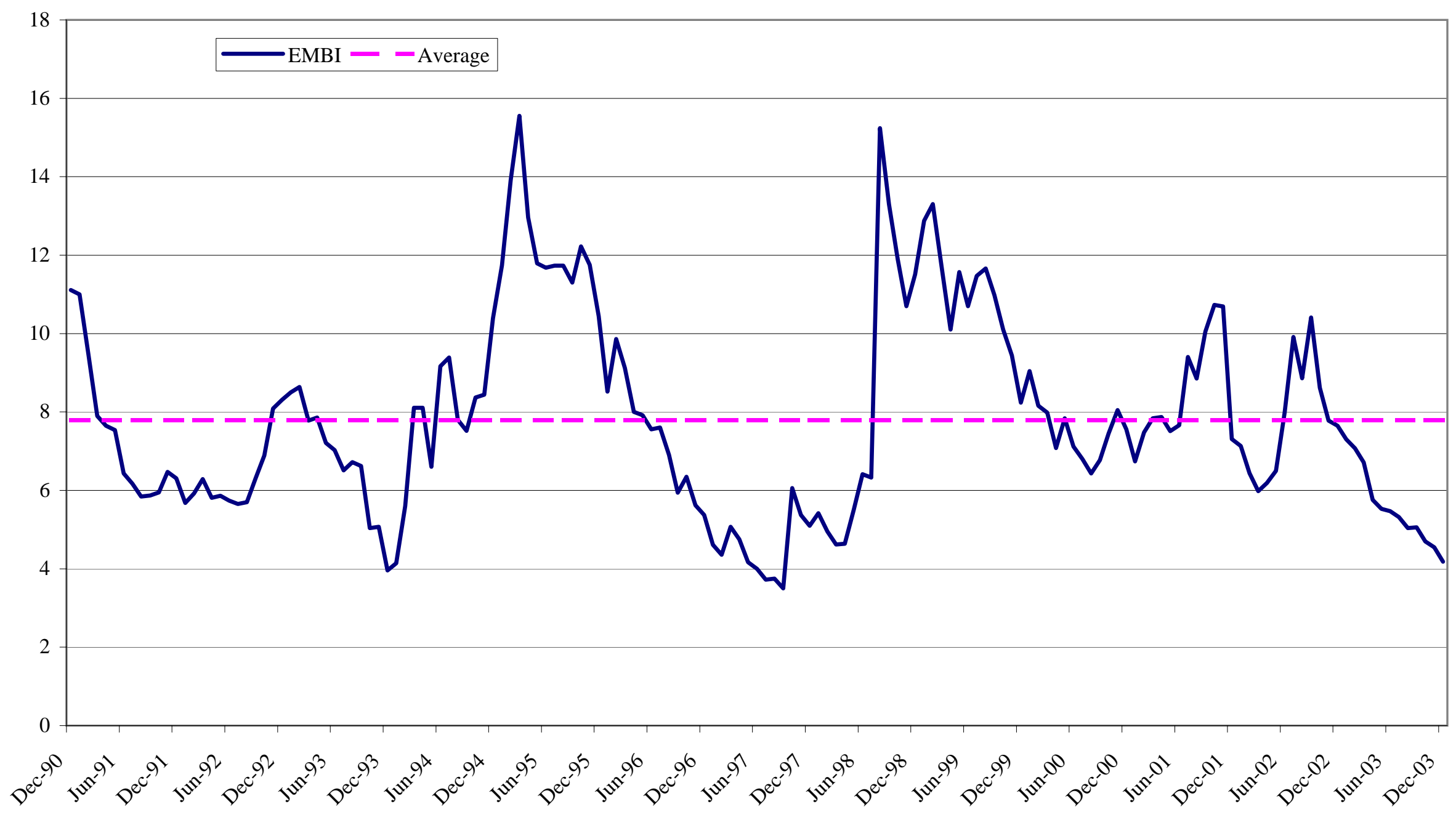


Figure 8: Alternative Welfare Comparison Using a First-Order Approximation

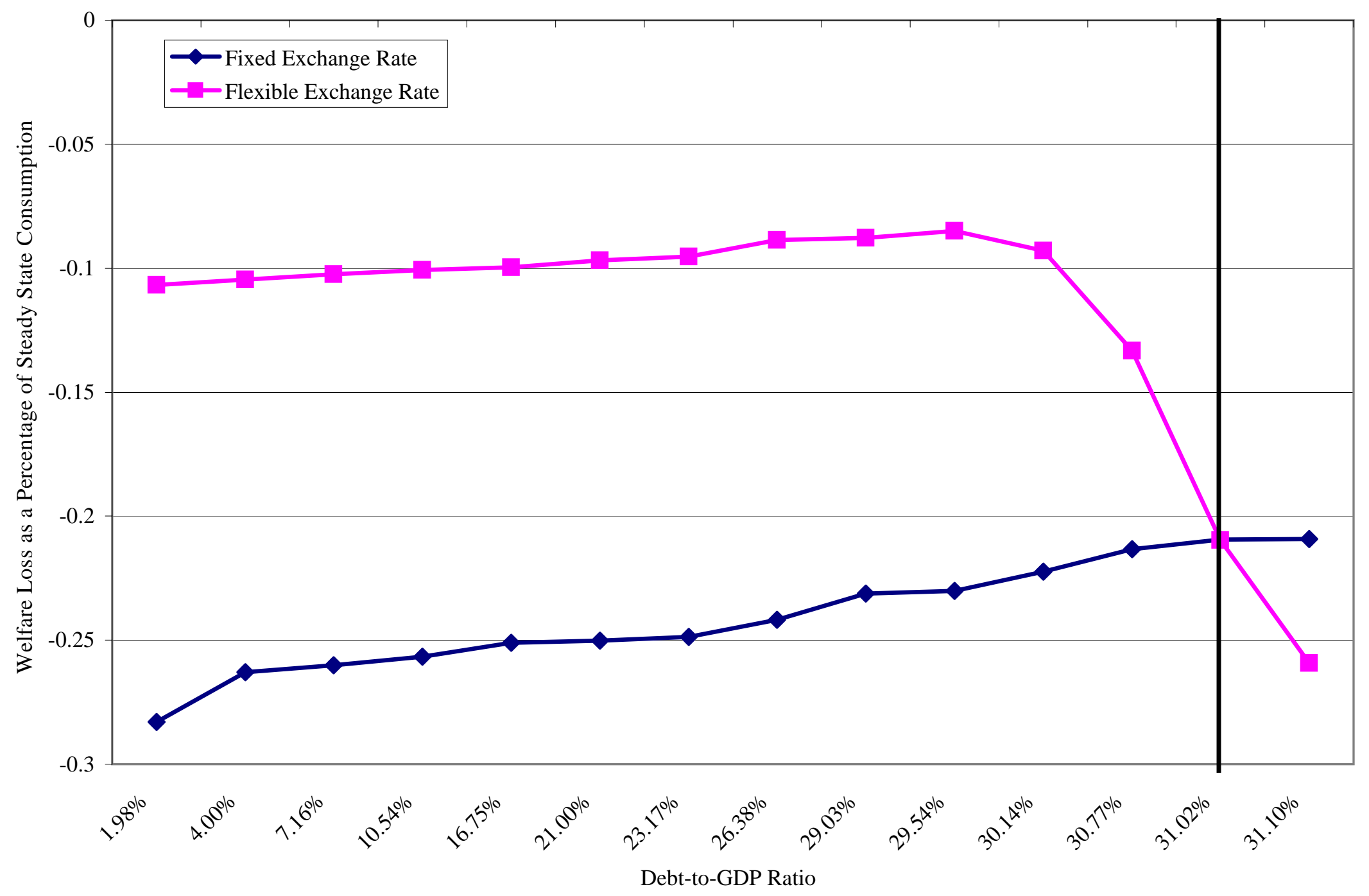


Figure 9: Alternative Welfare Comparison Using a Second-Order Approximation

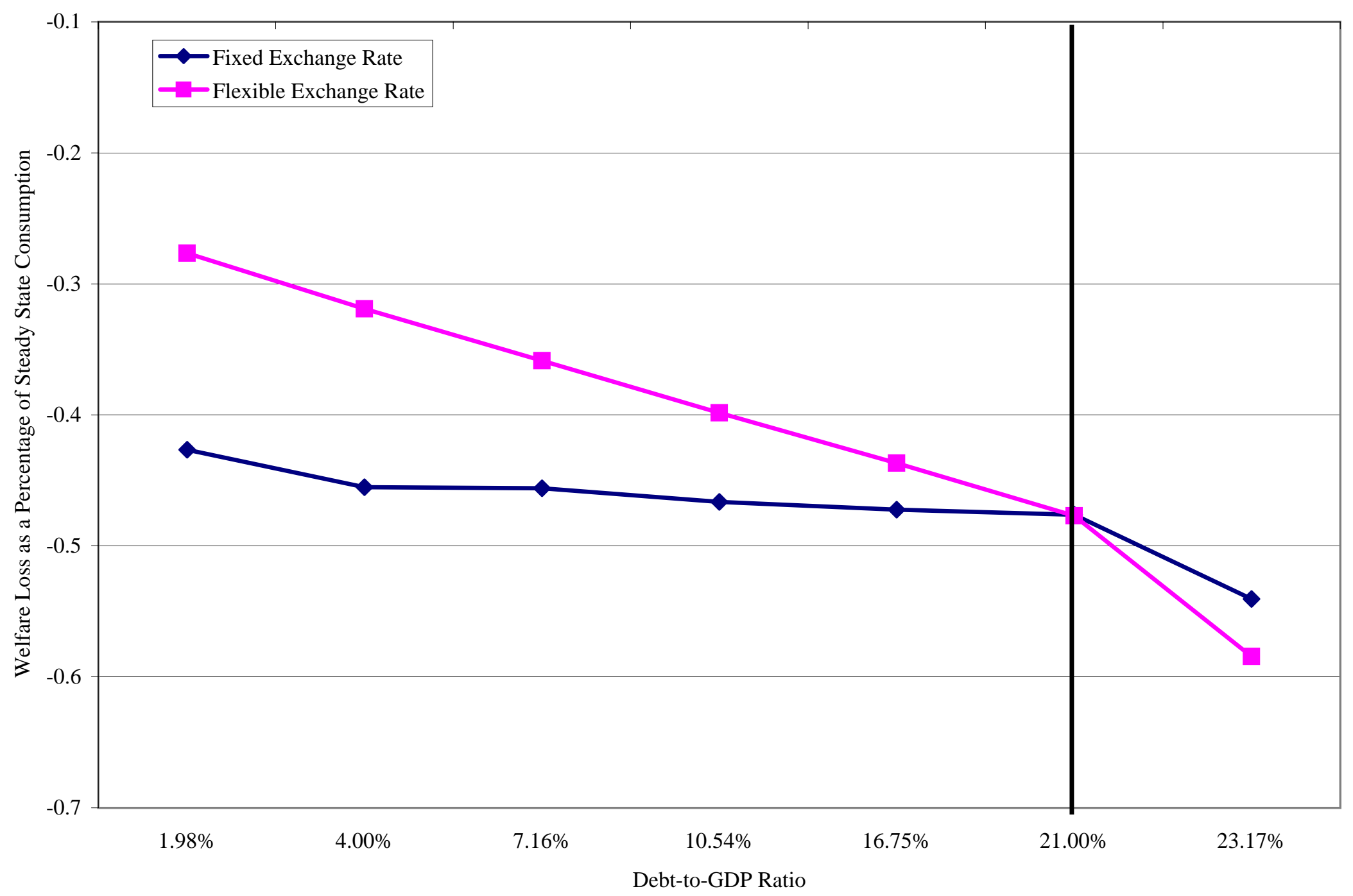




\section{References}

Bergin, Paul, and Ivan Tchakarov, 2003, "Does Exchange Rate Risk Matter for Welfare? A Quantitative Investigation,” NBER Working Paper No. 9900 (Cambridge, Massachusetts: National Bureau of Economic Research).

Bernanke, Ben, Mark Gertler, and Simon Gilchrist, 2000, "The Financial Accelerator in a Quantitative Business Cycle Framework," Handbook of Macroeconomics ( North Holland).

Calvo, Guillermo and Carmen Reinhart, 2001, "Fear of Floating," (unpublished; College Park, Maryland: University of Maryland).

Cespedes, Luis, 2000, "Credit Constraints and Macroeconomic Instability in a Small Open Economy," (unpublished; New York, New York: New York University).

Cespedes, Luis, Roberto Chang, and Andres Velasco, 2001, "Dollarization of Liabilities, Net Worth Effects, and Optimal Monetary Policy," (unpublished; New York, New York: New York University).

Cespedes, Luis, Roberto Chang, and Andres Velasco, 2002, "Balance Sheet and Exchange Rate Policy," (unpublished; Cambridge, Massachusetts: Harvard University).

Choi, Woon, and David Cook, 2004, "Liability Dollarization and the Bank Balance Sheet Channel," Journal of Monetary Economics, forthcoming.

Collard, Fabrice and Michel Juillard, 2003, "Stochastic Simulations with DYNARE. A Practical Guide," (unpublished; Toulouse, France: University of Toulouse).

Cook, David, and Michael Devereux, 2001, "The Macroeconomics of International Financial Panics," (unpublished; Vancouver, Canada: University of British Columbia).

Devereux, Michael and Philip Lane, 2003, "Exchange Rates and Monetary Policy in Emerging Market Economies," (unpublished: Dublin, Ireland: Trinity College).

Devereux, Michael, 2004, “ Monetary Policy Rules and Exchange Rate Flexibility in a Simple Dynamic General Equilibrium Model," (unpublished; Vancouver, Canada: University of British Columbia).

Elekdag, Selim, 2003, "Exchange Rate Regimes and Monetary Policy for Turkey," (unpublished: Washington, DC: International Monetary Fund).

Eichengreen, Barry, and Ricardo Hausman, 1999, "Exchange Rates and Financial Fragility," NBER Working Paper No. 7418 (Cambridge, Massachusetts: National Bureau of Economic Research). 
Friedman, Milton, 1953, Essays in Positive Economics, (Chicago: University of Chicago Press).

Gertler, Mark, Simon Gilchrist, and Fabio Natalucci, 2003, "External Constraints on Monetary Policy and the Financial Accelerator," BIS Working Paper No.139 (Basel, Switzerland).

Hunt, Benjamin, Peter Isard, and Douglas Laxton, 2002, "The Role of Exchange Rates in Inflation Targeting Regimes," (unpublished; Washington, DC: International Monetary Fund).

Juillard, Michel, and Douglas Laxton, 2003, “The IMF`s Global Economy Model: The Collection of DYNARE Programs Used for Model Solution and Analysis, “ (unpublished; Washington, DC: International Monetary Fund).

Kim, Jinill, and Sunghyan Kim, 2003, "Spurious Welfare Reversals in International Business Cycle Models," Journal of International Economics, Vol 60. pp. 471-500.

Kollmann, Robert, 2002, "Monetary Policy in the Open Economy: Effects on Welfare and Business Cycles," Journal of Monetary Economics, Vol.49, pp. 989-1015.

__ 2003, "Monetary Policy Rules in an Interdependent World," (unpublished; Bonn, Germany: University of Bonn).

Lane, Philip, and Gian Maria Milesi-Ferretti, 2002, "Long-Term Capital Movement," NBER Macroeconomics Annual 2001 (Cambridge, Massachusetts: National Bureau of Economic Research).

Rotemberg, Julio, 1982, "Sticky Prices in the United States," Journal of Political Economy, vol. 90, pp. 1187-1211.

Schmitt-Grohe, Stefanie, and Martin Uribe, 2001, "Stabilization Policy and the Costs of Dollarization," Journal of Money, Credit and Banking, Vol. 33, pp. 482-509.

Sims, C., 2000, "Second-order Accurate Solution of Discrete Time Dynamic Equilibrium Models," (unpublished; Princeton, New Jersey: Princeton University).

Straub, Roland, and Ivan Tchakarov, 2003, "Non-fundamental Exchange Rate Volatility and Welfare, “ (unpublished; Florence, Italy: European University Institute; Washington, DC: International Monetary Fund).

Woodford, Micheal, 2001, "Inflation Stabilization and Welfare," NBER Working Paper No. 9900 (Cambridge, Massachusetts: National Bureau of Economic Research). 